Universidade de São Paulo

Faculdade de Saúde Pública

\title{
ALIMENTAÇÃO FORA DO LAR E SUA RELAÇÃO \\ COM A QUALIDADE DA DIETA DE MORADORES DO \\ MUNICÍPIO DE SÃO PAULO: ESTUDO ISA-Capital
}

Bartira Mendes Gorgulho

Dissertação apresentada ao Programa de

Nutrição em Saúde Pública da Faculdade de

Saúde Pública da Universidade de São Paulo

para obtenção do título de Mestre em ciências.

Área de Concentração: Nutrição em Saúde

Pública

Orientadora: Profa. Dra. Dirce Maria Lobo Marchioni

São Paulo

2012 


\section{ALIMENTAÇÃO FORA DO LAR E SUA RELAÇÃO COM A QUALIDADE DA DIETA DE MORADORES DO MUNICÍPIO DE SÃO PAULO: ESTUDO ISA-Capital}

Bartira Mendes Gorgulho

Dissertação apresentada ao Programa de Nutrição em Saúde Pública da Faculdade de Saúde Pública da Universidade de São Paulo para obtenção do título de Mestre em ciências.

Área de Concentração: Nutrição em Saúde Pública

Orientadora: Profa. Dra. Dirce Maria Lobo Marchioni

São Paulo 
É expressamente proibida a comercialização deste documento tanto na sua forma impressa como eletrônica. Sua reprodução total ou parcial é permitida exclusivamente para fins acadêmicos e científicos, desde que na reprodução figure a identificação do autor, título, instituição e ano da dissertação. 
Dedicatória

À minha avó Laura (in memorian), pelo exemplo de perseverança, à minha mãe, por sempre me incentivar, ao meu pai, por acreditar. 


\section{Agradecimentos}

Á Professora e orientadora Dirce Maria Lobo Marchioni, pelos ensinamentos, respeito e confiança, pelo carinho e profissionalismo acima de tudo.

À Professora Regina Mara Fisberg, pelas boas risadas e companfia, por todo auxilio, minha grande "co-oeientadora".

À Professora Lígia Araújo Martini, minha tutora e "orientadora postiça", obrigada pela confiança.

Aos Professores Daniel Bandoni e Rafael Claro, por todo auxilio e disponibilidade, desde a iniciação científica.

Aos membros da CCP- Nutrição em Saúde Pública e todos os representantes discentes pelo apoio e incentivo.

À minha amiga Michelle Alessandra de Castro, pelo companheirismo e colaboração desde a iniciação científica.

À Valeria Baltar, por aguentar o meu mau humor todos os dias, por me ouvir e ser tão amiga.

À Bruna e ao Lucas, por tornarem a estatística mais divertida.

Ao Eliseu Verly Jr., por todos os momentos de risadas e descontração.

À todos os membros do GAC, pelo apoio e dedicação ao grupo. Antigas e novas gerações.

À Deborah, Carole Michelle, pelo apoio e amizade. À Caroline Dulley, Guto, Bianca e Si Carol, por estarem sempre presentes, independente da distância.

Ao Ninho, Kako, Dinda, Chimú, Canela e Hedlyn, por trazerem um pouco de Mogi a São Paulo. Às queridonas Mari e Raychell, por todas as lembranças. 
À Dona Lucila e a Dona Hilda, por todo carinho. Aos Barrences e Nepomucenos pela acolhida.

Aos "Epidemiologistas e agregados", por me receberem, pela amizade e convívio nas disciplinas da pós-graduação e no Finnegans. Às meninas da nutri, Dani, Camila, Jana, Ana Paula, Adriana, Juliana e Larissa, pelos auxílios e conversas no corredor.

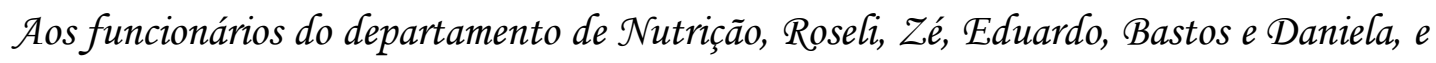
da Pós graduação, Vânia, Alessandra, Ulisses, Cidinha e Renilda, por estarem sempre dispostos e presentes.

Aos amigos Sergio, Marcellus, Cristiano, Adilson e Vivi, por fazerem da FSP um local de trabalho mais divertido.

À Tia Maria, Tio Milton, Marcela e Rafaela, por acreditarem e compreenderem, por me receberem. À Tia Vânia, por todo apoio e auxilio. Por incentivar e acreditar sempre.

Aos meus irmãos Gutoso, Guimi, Vini e Juju, cunhadas, Livia, Maíra e Helô, e aos meus sobrinhos Jobim, Lilás e Nina Simone, que eu tanto amo.

Aos meus pais, Silvia e Dimas, e agregados, Luis e Meire, por estarem sempre por perto, pela compreensão e incentivo.

À Fundação de Amparo à Pesquisa do Estado de São Paulo (FAPESP) pela concessão da 6olsa de Mestrado que muito contribuiu para a realização deste estudo.

$E$ a todos àqueles que, de alguma forma, participaram de momentos importantes em toda minha trajetória de vida. 
“Enquanto eu tiver perguntas

e não houver resposta, continuarei a escrever..."

Clarice Lispector 


\section{RESUMO}

Gorgulho BM. Alimentação fora do lar e sua relação com a qualidade da dieta de moradores do município de São Paulo: estudo ISA-capital [Dissertação de mestrado]. Programa de pós-graduação Nutrição em Saúde Pública, Faculdade de Saúde Pública, Universidade de São Paulo; 2012.

Introdução. A alimentação é considerada pela Organização Mundial da Saúde um dos principais fatores de risco modificáveis para doenças crônicas não transmissíveis, ressaltando a importância do entendimento dos hábitos alimentares e seus determinantes no atual cenário epidemiológico. Entretanto, pouco se sabe sobre as características nutricionais e as características dos usuários da alimentação fora do lar. Objetivo. Investigar a qualidade nutricional da alimentação fora do lar e sua relação com características sociais, demográficas e de estilo de vida. Materiais e métodos. Estudo transversal, de base populacional, por meio de inquérito domiciliar, com amostra de 232 adolescentes e 602 adultos e idosos. Foi aplicado questionário sobre hábitos de vida, condições sóciodemográficas, atividade física e inquérito alimentar, por meio do recordatório de $24 \mathrm{~h}$. As características das refeições realizadas fora do lar foram investigadas pelo uso do Índice de Qualidade da Refeição (IQR), com base nas recomendações da Organização Mundial da Saúde e Ministério da Saúde brasileiro. A associação entre alimentar-se fora do lar e a qualidade da dieta, verificada por meio do Índice de Qualidade da Dieta Revisado para a População Brasileira (IQD-R) foi investigada pelo uso de modelos de regressão linear múltiplo. A razão de prevalência de pessoas consumindo refeições fora do lar e sua associação com as características sociais, demográficas e de estilo de vida foi analisada através da regressão de Poisson com variância robusta. Resultados. Dentre os 834 entrevistados, $32 \%$ relataram ter realizado ao menos uma das três principais refeições (café da manhã, almoço e jantar) fora de casa. Foram detectadas associações estatisticamente significantes entre consumir alimentos fora do lar e ter excesso de peso. Pôde-se observar a presença tanto de alimentos marcadores de uma dieta saudável, a exemplo do arroz e feijão, como de alimentos integrantes de uma dieta não saudável, como refrigerantes, salgados, sanduíches e pizzas. O escore médio do Índice de Qualidade da Refeição realizada fora do lar foi de 42,62 (IC 95\%: 36,17-49,07) pontos no café da manhã; 42,54 (IC 95\%: 37,7547,34 ) pontos no almoço e 42,92 (IC 95\%: 36,47-49,38) pontos no jantar. Almoçar fora de casa apresentou associação negativa $(\mathrm{p}<0.05)$ com a qualidade da dieta, independente do sexo, renda familiar per capita e estado nutricional. Conclusão. Os achados sugerem que alimentar-se fora de casa pode contribuir como fator de risco modificável para DCNT, apresentando maior teor de gorduras total e saturada. No entanto, a qualidade nutricional das refeições realizadas dentro de casa também precisa ser melhorada.

Descritores: Alimentação fora do lar, qualidade da dieta, hábitos alimentares. 


\begin{abstract}
Gorgulho BM. Food consumption away from home and its relation to the dietary quality in São Paulo: study ISA-capital [Dissertation]. Programa de pós-graduação Nutrição em Saúde Pública, Faculdade de Saúde Pública, Universidade de São Paulo; 2012.
\end{abstract}

Background. Diet is considered by the World Health Organization a major modifiable risk factors for chronic diseases, emphasizing the importance of understanding the feeding habits and their determinants in the current epidemiological scenario. However little is known about the nutritional characteristics and the characteristics of users of food away from home. Objective. To investigate the nutritional quality of food away from home and their relationship to social, demographic and lifestyle. Methods. Crosssectional study, a population-based, through a household survey with a sample of 232 adolescents (12-19 years), 602 adults and elderly (20 years or more) of both sexes. Dietary intake was measured by application of $24 \mathrm{hR}$ by phone. The overall dietary quality was assessed by the Brazilian Healthy Eating Index Revised (B-HEIR) and the Meal Quality Index (MQI) was used to evaluate dietary quality of the main meals. The association between the B-HEIR and the MQI was assessed by linear regression analysis. The proportion of people that consumed meals away from home and its association with the social, demographic and lifestyle were analyzed by Poisson regression with robust variance. Results. Among the 834 respondents, $32 \%$ had at least one meal away from home. The average energy consumption per meal away from home was $628 \mathrm{kcal}$ (sd 101kcal), about $35 \%$ of the average daily consumption reported in this population. Statistically significant associations were found between food consumption away from home and overweight. It was observed the presence of both food markers of a healthy diet, such as rice and beans as food components of a unhealthy diet as soft drinks, snacks, sandwiches and pizzas. The average MQI score of lunch consumed away from home was lower than lunch at home, with higher amounts of total and saturated fats. Have lunch away from home was associated with the MQI score. Conclusion. Our findings suggest that eating meals away from home can contribute as a modifiable risk factor for chronic diseases, with higher levels of total and saturated fat. However, the meals consumed at home also need improvement.

Keywords: food habits, diet, feeding away from home 


\section{İNDICE}

1. INTRODUÇÃO.

1.2. ALIMENTAÇÃO FORA DO LAR

1.3. INQUÉRITOS POPULACIONAIS DE SAÚDE E NUTRIÇÃO.

2. JUSTIFICATIVA

3. OBJETIVO. 16

3.1. OBJETIVO GERAL 16

3.2. OBJETIVOS ESPECÍFICOS 17

4. MATERIAL E MÉTODOS. 17

4.1. CONTEXTUALIZAÇÃO . 17

4.2. DELINEAMENTO DO ESTUDO 17

4.3. CASUÍSTICA. 17

4.4. COLETA DOS DADOS 18

4.5. INSTRUMENTO DE COLETA DE DADOS 19 
4.6. VARIÁVEIS DE ESTUDO

4.7. ANÁLISE ESTATÍSTICA

5.1. Artigo 1

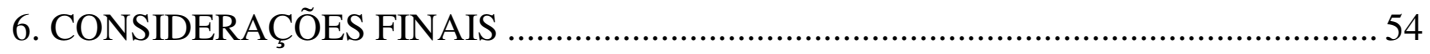

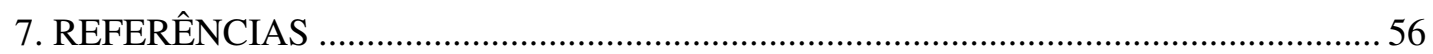

ANEXOS

Anexo 1 - Recordatório de 24 horas (R24h)

Anexo 2 - Roteiro para aplicação do R24h pelo Automated Multiple Pass Methods (AMPM) no Nutrition Data System for Research (NDSR) 66

Anexo 3 - Pareceres dos Comitês de Ética em Pesquisa .74

Anexo 4 - Termo de Consentimento Livre e Esclarecido .78

Currículo Lattes 81 


\section{$\underline{\text { Lista de Quadros }}$}

Quadro 1 - Variáveis utilizadas no estudo. São Paulo, 2012.

\section{$\underline{\text { Lista de Tabelas }}$}

Artigo 1:

Tabela 1 - Prevalência de alimentação fora do lar, razão de prevalência (RP) e intervalo de confiança em relação.

Tabela 2 - Frequência dos 15 principais grupos alimentares na alimentação fora do lar. São Paulo, 2010-2011.

Tabela 3 - Relação dos 15 principais grupos alimentares contribuintes em energia na alimentação fora do lar. São Paulo, 2010-2011.

Tabela 4 - Relação dos 15 principais grupos alimentares contribuintes de gorduras totais na alimentação fora do lar. São Paulo, 2010-2011.

Tabela 5 - Relação dos 15 principais grupos alimentares contribuintes de sódio na alimentação fora do lar. São Paulo, 2010-2011.

Tabela 6 - Contribuição dos grupos alimentares no consumo de açúcar de adição na alimentação fora do lar. São Paulo, 2010-2011.

Artigo 2:

Tabela 1 - Analysis on the scores for items in the Meal Quality Index. São Paulo, SP. 2010.

Tabela 2 - Mean score of B-HEIR for the controls variables and the linear regress model. São Paulo, SP. 2010. 


\section{$\underline{\text { Lista de Abreviaturas }}$}

ABERC - Associação Brasileira das Empresas de Refeições Coletivas AFL - Alimentação Fora do Lar

AMPM - Automated Multiple-Pass Method

BHEI-R - Brazilian Health Index Revised

CGAN- Coordenação Geral de alimentação e Nutrição

CNPQ - Conselho Nacional de desenvolvimento Científico e Tecnológico

DCNT - Doenças Crônicas não Transmissíveis

FAPESP - Fundação de Amparo à Pesquisa do Estado de São Paulo

FIESP - Federação das Indústrias do estado de São Paulo

HEI - Health Eating Index

IBGE - Instituto Brasileiro de Geografia e Estatística

IBOPE - Instituto Brasileiro de Opinião Pública e Estatística

IQ - Intervalo Interquartil

IQD-R - Índice de Qualidade da Dieta Revisado

IQR - Índice de Qualidade da Refeição

ISA - Inquérito de Saúde de São Paulo

MS - Ministério da Saúde

MQI - Meal Quality Index

NDS - Nutrition Data Sistem for Research

OMS - Organização Mundial da Saúde

PNAD - Pesquisa Nacional por Amostras de Domicílios 
POF - Pesquisa de Orçamentos Familiares

QFA - Questionário de Frequência Alimentar

R24h - Recordatório Alimentar de 24 horas

TCLE - Termo de Consentimento Livre e Esclarecido

USDA - United States Department of Agriculture

USP - Universidade de São Paulo

WHO - World Health Organization 


\section{APRESENTAÇÃO}

Esta dissertação está estruturada em formato de artigos científicos, sob o respaldo das diretrizes promulgadas pela Comissão de Pós-Graduação da Faculdade de Saúde Pública da Universidade de São Paulo em sua sessão 9ª/2008 de 05/06/2008, e atende às normas de apresentação das dissertações contidas no Guia de Apresentação de Teses desta instituição.

A dissertação está organizada nas seguintes seções: (1) Introdução, que aborda o conhecimento existente sobre o papel dos inquéritos populacionais de saúde e nutrição; os aspectos envolvidos entre a alimentação e as doenças crônicas não transmissíveis, e por fim, o consumo alimentar fora do lar; (2) Justificativa, destacando a relevância da investigação; (3) Objetivos, em que são descritos os propósitos do estudo, (4) Métodos, que contempla a contextualização, delineamento e casuística do estudo; (5) Resultados e Discussão, que inclui os manuscritos desenvolvidos, e (5) Considerações Finais, que sumariza os principais achados do estudo. 


\section{INTRODUÇÃO}

\subsection{ALIMENTAÇÃO E AS DOENÇAS CRÔNICAS NÃO TRANSMISSÍVEIS}

Segundo dados do Instituto Brasileiro de Geografia e Estatística (IBGE) o excesso de peso e a obesidade são encontrados com grande frequência, a partir de 5 anos de idade, em todos os grupos de renda e em todas as regiões brasileiras. A avaliação do estado nutricional dos jovens de 10 a 19 anos, considerando a relação entre IMC e idade com referencial da OMS, revela que o aumento de peso em adolescentes e adultos foi contínuo nos últimos 34 anos, resultando em cerca de metade dos homens e das mulheres, com pelo menos 20 anos de idade, com excesso de peso.

Atualmente, as doenças crônicas não transmissíveis (DCNT) são as principais causas de mortalidade e incapacidade no mundo, sendo responsáveis por $60 \%$ dos 56,5 milhões de óbitos anuais (WHO, 2002). Obesidade, hipercolesterolemia, tabagismo e hipertensão têm sido reconhecidos como os principais fatores de risco para doenças cardiovasculares (GRAVINA-TADDEI et al, 2005). No Brasil, as doenças cardiovasculares são as principais causas de morte em todas as regiões, respondendo por quase um terço dos óbitos (MALTA et al, 2006).

Este panorama esta associado com as mudanças nos padrões alimentares: aumento do consumo de gordura, excesso de açúcar e consumo insuficiente de frutas e hortaliças, o que leva a um aumento da densidade energética das dietas (MONTEIRO et al, 1995; MONTEIRO e col., 2000; LEVY-COSTA et al, 2005).

A ingestão diária de frutas, legumes e verduras está abaixo dos níveis recomendados pelo Ministério da Saúde (400g) para mais de $90 \%$ da população. Já as bebidas com adição de açúcar (sucos, refrescos e refrigerantes) têm consumo elevado, especialmente entre os adolescentes, que ingerem o dobro da quantidade registrada para adultos e idosos, além de apresentarem alta frequência de consumo de biscoitos, 
linguiças, salsichas, mortadelas, sanduíches e salgados (IBGE, 2011).

\subsection{ALIMENTAÇÃO FORA DO LAR}

Os resultados da Pesquisa de Orçamento Familiar (POF) realizada em 2008 e 2009 sugerem a tendência do brasileiro em fazer suas refeições fora do lar. Em seis anos (2002/03-2008/09), a participação urbana da alimentação fora do domicílio nos gastos com alimentação subiu de um quarto $(25,7 \%)$ para um terço $(33,1 \%)$, e a rural subiu de $13,1 \%$ para $17,5 \%$. Com destaque para a região sudeste onde o percentual cresceu de 26,9\% para 37,2\%. Em 2008 o consumo médio de calorias fora do domicílio correspondeu a aproximadamente $16 \%$ da ingestão calórica total e foi maior nas áreas urbanas, na região Sudeste, entre os homens e para indivíduos na faixa de renda familiar per capita mais elevada. CLARO et al (2009), ao analisarem a influência da renda sobre as despesas com alimentação fora do domicílio, sugerem que a evolução favorável da renda, principalmente nos estratos mais pobres da população, resulta em aumento da participação dessa forma de se alimentar, acarretando, possivelmente, na redução da qualidade nutricional da alimentação no país.

Segundo pesquisa realizada pelo FIESP e IBOPE (2010), sob encomenda do projeto Brasil Food Trens, 27\% das refeições realizadas fora do lar ocorrem em restaurantes por peso e 19\% em redes de fast-food. Dados da Associação Brasileira das Empresas de Refeições Coletivas - ABERC (2011), o mercado de refeições coletivas servia 7,5 milhões de refeições em 1998, passando para 14,89 milhões em 2010.

A alimentação fora do lar pode ser definida de duas formas, a primeira como todos os alimentos preparados fora de casa, independente do local onde serão consumidos; e, a segunda, como todos os alimentos consumidos fora de casa, independente de onde são preparados, incluindo lanches feitos em casa para consumo em outros locais (BURNS et al.).

Estudos evidenciam que a alimentação fora de casa tem maior densidade 
energética, com maiores quantidades de gorduras, gorduras saturadas e menor quantidade de micronutrientes (LIN et al, 1999; KANT et al, 2000; KEARNEy et al, 2001). Além disso, a maior participação da alimentação fora do domicílio também se associa a maiores prevalências de excesso de peso e sedentarismo (MA et al, 2003; NILSEN et al, 2004; ORFANOS et al, 2007).

ZIEGLER et al (2006) ao analisarem no Estados Unidos a alimentação de 632 crianças e adolescentes observaram que as refeições realizadas fora do lar apresentavam uma maior freqüência de alimentos açucarados e ricos em gordura trans quando comparados a alimentação preparada em casa. Alguns estudos sugerem que a qualidade nutricional do alimento escolhido para consumo fora do lar está inversamente relacionada com a densidade geográfica de restaurantes do tipo fast-food, que usualmente oferecem alimentos com maior densidade energética, maior conteúdo de gordura, colesterol e sódio (MADDOCK et al 2004, STURM E DATAR 2005,INAGAMI et al 2006, MORLAND et al 2006).

ORFANOS et al (2010), ao compararem as características da alimentação dentro e fora do lar de indivíduos de 10 cidades de diferentes países da Europa, observaram que alimentos como açúcares e doces; chá e cafés e bebidas alcoólicas apresentaram maior contribuição para as calorias provenientes da alimentações fora do lar.

ABREU et al.(2005), ao avaliarem as refeições servidas por quatro restaurantes por peso da cidade de São Paulo, observaram que todos estavam acima das recomendações atuais para ingestão calórica e lipídica, contribuindo, assim, potencialmente, para o desenvolvimento de DCNT.

BEZERRA E SICHIERI (2009) mostraram que a prevalência de sobrepeso e obesidade em homens que se alimentavam fora do lar (38,5\% e 11,9\%) foi maior que a prevalência em homens que não realizavam esse tipo de refeição (36,1\% e 10,3\%).

Embora o Ministério da Saúde (2006) reconheça que o hábito de fazer refeições 
fora de casa possa estar contribuindo para o aumento da prevalência de obesidade, pouco se sabe, no Brasil, sobre as características nutricionais dessas refeições.

\subsection{INQUÉRITOS POPULACIONAIS DE SAÚDE E NUTRIÇÃO}

O consumo alimentar está associado com prevenção ou risco de doenças e por isso sua estimativa pode ser utilizada como importante fonte de informação para o planejamento de políticas públicas em nutrição (WOTWKI, 2003). A Estratégia Global para Alimentação, Atividade Física e Saúde da Organização Mundial da Saúde (OMS) destaca a necessidade de adequação dos padrões alimentares em todo o mundo, apontados como os responsáveis diretos pelo crescimento das doenças crônicas não transmissíveis (DCNT), em especial da obesidade.

Inquéritos populacionais de saúde vêm sendo realizados com frequiência cada vez maior no Brasil. Quando periódicos, constituem informação essencial para os sistemas de informação utilizados para a formulação e avaliação das políticas sociais e de saúde (VIACAVA, 2002). Na área de alimentação e nutrição, possibilitam ainda a obtenção de informação pontual sobre o estado nutricional e ingestão do grupo estudado. A vantagem deste tipo de pesquisa é a obtenção de informações básicas que nortearão avaliações periódicas posteriores. Entretanto, o alto custo e o desgastante trabalho operacional são limitações que, muitas vezes, acabam reduzindo a periodicidade e o tamanho das amostras, dificultando o diagnóstico preciso de problemas nutricionais.

As informações de inquéritos populacionais em alimentação e nutrição estão entre as estratégias de vigilância epidemiológica utilizadas pela Coordenação Geral de Alimentação e Nutrição (CGAN) do Ministério da Saúde (MS) para implementação da vigilância alimentar e nutricional no Brasil (COUTINHO et al., 2009).

A vigilância alimentar e nutricional corresponde à descrição contínua e o acompanhamento de tendências das condições de alimentação e nutrição da população, 
assim como de seus fatores determinantes. Estas informações auxiliam a embasar o planejamento, monitoramento e gerenciamento de programas para melhoria dos padrões de consumo alimentar e de estado nutricional da população (BRASIL, 2008).

A realização periódica de pesquisas de avaliação do consumo alimentar propicia a formação de séries temporais, essenciais para a identificação de mudanças no padrão dietético por estratos socioeconômicos e áreas geográficas, a fim de, posteriormente, formular políticas nutricionais em saúde pública (MONTEIRO et al., 2000). Quando as pesquisas são realizadas com coleta de dados domiciliar, representam um grande avanço para os estudos de consumo alimentar devido a sua contribuição para o aumento da precisão das estimativas da ingestão de alimentos (LUSTOSA, 2000).

\section{JUSTIFICATIVA}

A alimentação é considerada pela Organização Mundial da Saúde um dos principais fatores de risco modificáveis para DCNT, ressaltando a importância do entendimento dos hábitos alimentares e seus determinantes no atual cenário epidemiológico. Entretanto pouco se sabe sobre as características nutricionais e as características dos usuários da alimentação fora do lar. Assim, ao investigar as características nutricionais da alimentação fora do lar, proposta deste trabalho, espera-se contribuir preenchendo uma lacuna do conhecimento, de forma a oferecer subsídios para o planejamento e implementação de ações de promoção da alimentação saudável.

\section{OBJETIVO}

\subsection{OBJETIVO GERAL}

Investigar a qualidade nutricional da alimentação fora do lar e sua relação com características sociais, demográficas e de estilo de vida. 


\subsection{OBJETIVOS ESPECÍFICOS}

- Investigar a composição nutricional da alimentação fora do lar;

- Identificar os alimentos que participam do consumo realizado fora do lar;

- Investigar a qualidade das refeições realizadas fora do lar;

- Verificar a associação entre a alimentação fora do lar e a qualidade da dieta;

- Investigar a prevalência e razão de prevalência de indivíduos consumindo refeições fora do lar segundo características sociais, demográficas e de estilo de vida.

\section{MATERIAL E MÉTODOS}

\subsection{CONTEXTUALIZAÇÃO}

O presente projeto utilizou dados da pesquisa intitulada "Fatores dietéticos, homocisteína, polimorfismos do gene MTHFR e risco cardiovascular em adultos e idosos: estudo de base populacional" (ISA-2008), estudo transversal, de base populacional, financiado pelo CNPq, processo no. 461176/2008-0, edital MCT/CNPq 14/2008, Universal e pela Fundação de Amparo a Pesquisa de São Paulo (FAPESP processo ${ }^{\circ}$ 2009/15831-0), cujos dados foram coletados entre 2010 e 2011.

O ISA-2008 constituí-se de uma sub-amostra de indivíduos participantes do estudo intitulado "Inquérito de Saúde de Base Populacional no Município de São Paulo" (ISA-Capital), inquérito domiciliar de saúde, de base populacional, financiado pela Secretaria Municipal de Saúde de São Paulo e conduzido em 2008 e 2009.

\subsection{DELINEAMENTO DO ESTUDO}

Estudo transversal, de base populacional, por meio de inquérito domiciliar e telefônico.

\subsection{CASUÍSTICA}


No ISA-Capital, foram definidos oito domínios de estudo formados pelos grupos sexo/idade, sendo, para cada grupo, planejado a realização de 420 entrevistas, perfazendo um tamanho amostral total de 3360 indivíduos. Esses domínios amostrais foram: menores de um ano, de 1 a 11 anos de idade, 12 a 19 anos masculino; 12 a 19 anos feminino; 20 a 59 anos masculino; 20 a 59 anos feminino; 60 anos e mais masculino e 60 anos e mais feminino (CESAR et al., 2005).

Foram sorteados 60 setores censitários dentre os 220 pertencentes à amostra da Pesquisa Nacional por Amostra de Domicílios - PNAD, realizada em 2003 pelo IBGE, e que haviam sido sorteados com probabilidade proporcional ao tamanho. Os domicílios foram sorteados a partir das listagens elaboradas pelo IBGE durante o trabalho de campo da PNAD.

Em cada setor, planejou-se a obtenção de 7 entrevistas de cada grupo sexo/idade de interesse e para se precaver da perda de $20 \%$ de unidades da amostra em função da não resposta, foi previsto o sorteio de 8,75 pessoas em cada grupo sexo/idade $(7 / 0,8=8,75)$.

Para o ISA-2008, foram convidados a participar 900 indivíduos de ambos os sexos (300 adolescentes, 300 adultos e 300 idosos) entrevistados no ISA-Capital. O tamanho mínimo de 300 possibilita estimar uma prevalência de 0,5 com erro de 0,07, níveis de confiança de $95 \%$ e um efeito de delineamento de 1,5. Dessa forma a casuística constitui-se de amostra final de 232 adolescentes (12 a 19 anos), 304 adultos (20 a 59 anos) e 298 idosos (60 anos ou mais) de ambos os sexos do estudo ISA-2008, que haviam anteriormente participado do ISA-Capital e consentiram em participar.

\subsection{COLETA DOS DADOS}

Foi aplicado o questionário sobre hábitos de vida, condições sócio-demográficas, atividade física, R24h e questionário de frequêencia alimentar semiquantitativo. Medidas antropométricas, pressão arterial e amostra de material biológico também foram aferidas 
no domicílio por enfermeiro treinado.

\subsection{INSTRUMENTO DE COLETA DE DADOS}

\subsubsection{INQUÉRITO ALIMENTAR}

O consumo alimentar foi medido por meio da aplicação do R24h (ANEXO 1) utilizando o método AMPM (Automated Multiple-Pass Method). Neste método, o respondente é guiado por meio de cinco passos (listagem rápida; revisão da listagem rápida; nomeação das refeições; ciclo de detalhamento e revisão geral), em um processo padronizado, que visa manter o indivíduo interessado e engajado na entrevista, ajudando-o a se recordar de todos os itens consumidos. Dessa forma, enseja que os dados obtidos sejam mais fidedignos.

Para padronização na coleta de dados foi realizado treinamento dos entrevistadores, com utilização de formulário padrão para aplicação do R24h e manual explicativo para o seu preenchimento. As coletas foram realizadas aleatoriamente entre os dias da semana e meses do ano.

Anteriormente à digitação dos dados de consumo alimentar, as informações contidas em cada R24h foram checadas a fim de monitorar a qualidade das entrevistas e definir a padronização para quantidades e receitas. Os recordatórios alimentares foram convertidos em valores de nutrientes utilizando o software Nutrition Data System for Research (NDS, versão 2007, Nutrition Coordinating Center [NCC], University of Minnesota, Minneapolis), que tem como principal base de dados a tabela de composição de alimentos americana (USDA). O segundo R24h, aplicado por telefone, utilizou o mesmo método AMPM e foi realizado diretamente no software Nutrition Data System for Research (ANEXO 2).

No entanto, devido à ausência de informações sobre o local de consumo dos alimentos relatados como consumidos no primeiro recordatório alimentar de $24 \mathrm{~h}$, optouse trabalhar apenas com os dados obtidos no segundo recordatório alimentar. Os 
indivíduos com ingestão de energia inferior a 500 e/ou superior a $5000 \mathrm{kcal}$ foram excluídos da análise (WILETT, 1998).

\subsection{VARIÁVEIS DE ESTUDO}

\begin{tabular}{|c|c|c|}
\hline Variável & Tipo & Categorização \\
\hline \multirow[t]{2}{*}{ Alimentação fora do lar } & \multirow[t]{2}{*}{ Dependente } & $0=$ não consome \\
\hline & & $1=$ consome \\
\hline Índice de qualidade da dieta revisado & Dependente & contínua \\
\hline \multirow[t]{4}{*}{ Refeição consumida fora de casa } & \multirow[t]{4}{*}{ Independente } & $0=$ nenhuma \\
\hline & & $1=$ café da manhã \\
\hline & & $2=$ almoço \\
\hline & & $3=$ jantar \\
\hline \multirow[t]{2}{*}{ Sexo } & \multirow[t]{2}{*}{ Independente } & $0=$ masculino \\
\hline & & $1=$ feminino \\
\hline \multirow[t]{3}{*}{ Idade } & \multirow[t]{3}{*}{ Independente } & $0=12-19$ anos \\
\hline & & $1=20-59$ anos \\
\hline & & $2=60$ anos ou mais \\
\hline \multirow[t]{3}{*}{ Renda familiar per capta } & \multirow[t]{3}{*}{ Independente } & $0=$ Até dois salários mínimos \\
\hline & & 1=3-6 sálarios mínimos \\
\hline & & $2=6$ ou mais salários mínimos \\
\hline \multirow[t]{3}{*}{ Tabagismo } & \multirow[t]{3}{*}{ Independente } & $0=$ Nunca \\
\hline & & $1=$ Ex-fumante \\
\hline & & $2=$ Fumante \\
\hline \multirow[t]{2}{*}{ Etilismo } & \multirow[t]{2}{*}{ Independente } & $0=$ não \\
\hline & & $1=\operatorname{Sim}$ \\
\hline \multirow[t]{2}{*}{ Estado nutricional } & \multirow[t]{2}{*}{ Independente } & $0=$ baixo peso/eutrófico \\
\hline & & $1=$ sobrepeso/obesidade \\
\hline
\end{tabular}

\subsection{ANÁLISE ESTATÍSTICA}

Os dados foram tratados estatisticamente utilizando-se o software Stata (versão 10), com as correções necessárias ao desenho amostral através do módulo "Survey”. 


\subsection{ASPECTOS ÉTICOS}

$\mathrm{O}$ projeto de pesquisa utilizou dados secundários dos projetos mencionados acima, que foram aprovados pelo Comitê de Ética da Secretaria Municipal de Saúde e pelo Comitê de Ética da Faculdade de Saúde Pública, atendendo às exigências da resolução nº 196 de 10 de outubro de 1996 do Conselho Nacional de Saúde que regulamenta pesquisas envolvendo seres humanos (ANEXO 3). A participação dos sujeitos foi feita mediante assinatura do Termo de Consentimento Livre e Esclarecido (ANEXO 4) pelo responsável legal ou pelo próprio indivíduo, quando maior de 18 anos.

\section{RESULTADOS E DISCUSSÃO}

\subsection{Artigo 1}

Alimentação fora do lar: prevalência e padrão nutricional em uma metrópole multicultural

Bartira M. Gorgulho, Regina M. Fisberg e Dirce Maria L. Marchioni Artigo submetido à revista Cadernos de saúde Pública

\section{Resumo}

Este estudo objetivou caracterizar as refeições realizadas fora do lar, identificando proporção e contribuição dos alimentos que as compõem para o consumo diário energético,de gordura, sódio e açúcar de adição. O consumo alimentar foi medido por aplicação telefônica do R24h. Dentre os 834 entrevistados, 32\% realizaram ao menos uma refeição fora de casa. O consumo energético médio por refeição realizada fora do 
lar foi de $628 \mathrm{kcal}$ (dp 101kcal), cerca de 35\% da média de consumo diário relatado nesta população. Pôde-se observar a presença tanto de alimentos marcadores de uma dieta saudável, a exemplo do arroz e feijão, como de alimentos integrantes de uma dieta não saudável como refrigerantes, salgados, sanduíches e pizzas. Foi detectada associação estatisticamente significante entre o consumo alimentar fora do lar e sobrepeso.

Palavras-chave: alimentação fora do lar, qualidade da dieta, hábitos alimentares.

\begin{abstract}
This study aimed to characterize meals consumed away from home, identifying proportion and contribution of foods that make up for the daily intake of energy, fat, sodium and added sugar. Dietary intake was measured by application of $24 \mathrm{hR}$ by phone. Among the 834 respondents, $32 \%$ had at least one meal away from home. The average energy consumption per meal away from home was $628 \mathrm{kcal}$ (sd 101kcal), about 35\% of the average daily consumption reported in this population. It was observed the presence of both food markers of a healthy diet, such as rice and beans as food components of a unhealthy diet as soft drinks, snacks, sandwiches and pizzas. Statistically significant association was found between food consumption away from home and overweight.
\end{abstract}

\title{
Introdução
}

As crescentes taxas de sobrepeso e obesidade observadas nas últimas décadas têm sido associadas ao aumento no número de refeições realizadas fora do lar, sob a suposição destas serem mais densas energeticamente e apresentarem maiores quantidades de gorduras, sobretudo do tipo saturada, e menores quantidades de micronutrientes que as refeições preparadas no domicílio. ${ }^{1-7}$

Os resultados da Pesquisa de Orçamento Familiar (POF) realizada nos anos de 
2002/03 e 2008/09 sugerem a tendência do brasileiro em fazer suas refeições fora do lar. ${ }^{8}$ Em seis anos, a participação da alimentação fora do domicílio nos gastos com alimentação na área urbana subiu de $26 \%$ para $33 \%$, e na rural de $13 \%$ para $17,5 \%$. Também se observou elevada expansão no mercado brasileiro de refeições coletivas, que de 7,5 milhões de refeições servidas em 1998, ultrapassou 16,5 milhões em $2011 .{ }^{9}$

No Brasil, embora o Ministério da Saúde $(2006)^{10}$ reconheça que o hábito de fazer refeições fora de casa possa contribuir para o aumento da prevalência de obesidade, pouco se sabe sobre a composição dessas refeições. Assim, o objetivo do estudo foi caracterizar as refeições realizadas fora do lar, identificando a frequencia das refeições realizadas fora do lar (café da manhã, almoço e jantar) e a contribuição dos alimentos que as compõem para o consumo diário energético, de gordura, sódio e açúcar de adição em participantes de inquérito de saúde de base populacional na cidade de São Paulo - ISA-Capital.

\section{Métodos}

Trata-se de um estudo transversal de base populacional representativo do município de São Paulo, realizado por meio de inquérito domiciliar e telefônico. A população de estudo foi formada por uma sub-amostra do Inquérito de Saúde de São Paulo (ISA- Capital) conduzido em 2008 e 2009. ${ }^{11}$

Foram convidados a participar do estudo 900 indivíduos de ambos os sexos 300 adolescentes (12 a 19 anos), 300 adultos (20 a 59 anos) e 300 idosos (60anos ou mais) entrevistados no ISA-Capital. O tamanho mínimo de 300 possibilitaria estimar uma prevalência de 0,5 com erro de 0,07, níveis de confiança de $95 \%$ e um efeito de delineamento de 1,5; no entanto, devido a perdas por mudança de endereço, recusa e falecimento, a amostra final do estudo foi de 834 indivíduos (41\% do sexo masculino), sendo: 232 adolescentes, 304 adultos e 298 idosos. A amostra do ISA- Capital foi constituída pelos residentes em área urbana, em domicílios particulares ou coletivos do município de São Paulo. Para o sorteio, foram adotados procedimentos da 
amostragem estratificada por conglomerados em dois estágios, os setores censitários urbanos constituíram as unidades primárias de amostragem e os domicílios as secundárias.

No ISA-Capital os indivíduos foram questionados no domicilio sobre hábitos de vida, condições sócio-demográficas, consumo alimentar (primeiro R24h) e atividade física (Questionário Internacional de Atividades Físicas - IPAC versão longa) por entrevistadores treinados. No entanto, devido à ausência de informações sobre o local de consumo das refeições no primeiro R24h, o consumo alimentar foi medido novamente na subamostra, aleatoriamente entre os dias da semana e meses do ano, por aplicação telefônica de um segundo R24h. Para isso, utilizou-se o método AMPM (Automated Multiple-Pass Method) ${ }^{12}$, desenvolvido pelo Departamento de Agricultura dos Estados Unidos (USDA) e incorporado ao software Nutrition Data System for Research (NDS, versão 2007, Nutrition Coordinating Center [NCC], University of Minnesota, Minneapolis) ${ }^{13}$, que tem como principal base de dados a tabela de composição de alimentos norte-americana (USDA Food Composition Database). Neste método, o respondente é guiado por meio de cinco passos (listagem rápida; revisão da listagem rápida; nomeação das refeições; ciclo de detalhamento e revisão geral), em um processo padronizado, que visa manter o indivíduo interessado e engajado na entrevista, ajudando-o a se recordar de todos os itens consumidos (REF). ${ }^{12}$

A contribuição do consumo alimentar fora do lar por refeição, considerando-se apenas a segunda medida do R24h, foi obtida por meio da metodologia descrita por BLOCK et al. (1985). ${ }^{14}$ Este método considera não só o número de respondentes que relataram o consumo de um determinado alimento, como também o tamanho da porção e o conteúdo de nutrientes e energia. Para tanto, neste estudo, definiu-se como alimentação fora do lar (AFL) a refeição realizada fora do domicílio, independente do local de preparo, conforme declarado no R24h.

Os 309 alimentos relatados como consumidos por pelo menos 5\% da amostra 
foram agrupados em 34 grupos de acordo com a composição nutricional, os hábitos alimentares da população paulistana, dados da literatura e aplicação culinária, sendo eles: arroz; massas; pães, torradas e biscoitos; pães integrais; frutas; verduras; vegetais em conserva (enlatados); legumes; carne bovina; carne suína; carne processada; frios; aves; queijos amarelos; queijos brancos e requeijão; leite integral; leite semidesnatado e desnatado; lácteos (iogurtes e vitaminas de frutas); ovos; feijões carioca e preto; manteiga e margarina; doces; salgados, sanduíches e pizzas; café e chás; refrigerante; suco de frutas; bebidas alcoólicas; tempero para salada (óleo, sal, vinagre); açúcar refinado; molhos; condimentos naturais (cebola, alho, ervas); achocolatado; petiscos (batata frita, mandioca frita); leguminosas.

As variáveis de controle utilizadas no modelo de regressão múltipla de Poisson foram: sexo (masculino, feminino), idade (12 a 19 anos, 20 a 59 anos, 60 anos ou mais), renda familiar per capita (até dois salários mínimos, 3 a 6 salários mínimos, 6 ou mais salários mínimos), tabagismos (não fumante, ex-fumante, fumante), etilismo (não, sim), atividade física (insuficientemente ativo, ativo, muito ativo) e estado nutricional (sem excesso de peso, com excesso de peso). Todas as variáveis com significância menor que 0.20 na análise univariada foram consideradas candidatas ao modelo multivariado (stepwise forward). Todas as análises foram realizadas no módulo "Survey" do software Stata (versão 10) $)^{15}$.

O estudo foi aprovado pelo Comitê de Ética da Faculdade de Saúde Pública, atendendo às exigências da resolução n 196 de 10 de outubro de 1996 do Conselho Nacional de Saúde que regulamenta pesquisas envolvendo seres humanos. A participação dos sujeitos esteve condicionada à assinatura do Termo de Consentimento Livre e Esclarecido pelo responsável legal ou pelo próprio indivíduo, quando maior de $18 \backslash$ anos.

\section{Resultados}


Dentre os 834 entrevistados, 32\% (70 adolescentes, 156 adultos e 40 idosos) relataram ter realizado ao menos uma das três principais refeições (café da manhã, almoço e jantar) fora de casa. Destes $42 \%$ eram do sexo masculino e $58 \%$ apresentavam renda familiar per capita inferior a dois salários mínimos. A prevalência de excesso de peso, obesidade, hipertensão arterial e diabetes referida entre os que se alimentaram fora de casa foi de 51\% (IC 95\%: 42-59\%), $8 \%$ (IC 95\%: 2-14\%), 26.\% (IC 95\%: 17-34\%) e 4\% (IC 95\%: 2-6\%), respectivamente.

Não foram detectadas associações estatisticamente significantes entre o consumo alimentar fora do lar e as variáveis, com exceção do estado nutricional e do hábito de fumar, na categoria ex-fumante (tabela 1).

A tabela 2 mostra a frequência dos grupos de alimentos na alimentação fora do lar. Das 482 refeições realizadas fora do lar, 15\% eram café da manhã, 30\% almoço e $10 \%$ jantar, os $45 \%$ restantes referem-se às refeições intermediárias, isto é, aos lanches da manhã, tarde e/ou noite. Considerando apenas as três refeições principais (café da manhã, almoço e jantar) realizadas fora do lar, $36 \%$ foram realizadas no trabalho, $2 \%$ na escola, $26 \%$ em restaurantes e lanchonetes e $36 \%$ em outros ambientes.

O consumo energético médio no café da manhã, almoço e jantar fora do lar foi de $326 \mathrm{kcal}$ (dp $175 \mathrm{kcal}), 771 \mathrm{kcal}$ (dp $490 \mathrm{kcal}$ ) e $695 \mathrm{kcal}$ (dp $481 \mathrm{kcal})$, representado cerca de $20 \%, 47 \%$ e $42 \%$, respectivamente, da média do consumo diário relatado nesta população. Destas, no café da manhã, $12 \%$ (dp 8\%) eram provenientes do consumo de proteínas, 34\% (dp 22\%) de gorduras totais e 55\% (dp 34\%) de carboidratos; com 21\% (dp 14\%) de proteínas, 32\% (dp 26\%) de gorduras totais e 45\% (dp 28\%) de carboidratos no almoço e 20\% (dp 19\%) de proteínas, 32\% (dp 26\%) de gorduras totais e 44\% (dp 28\%) de carboidratos no jantar. O café da manhã, almoço e jantar, fora do lar representaram 5\% (dp 3\%), 20\% (dp 13\%) e 17\% (dp 16\%) do consumo médio diário de proteínas, $22 \%$ (dp 14\%), 47\% (dp 39\%) e 43\% (dp 35\%) do consumo médio diário de gorduras totais, 62\% (dp 39\%), 120\% (dp 75\%) e 106\% (dp 68\%) do consumo 
médio diário de carboidratos, respectivamente. Já o consumo médio diário de sódio foi de 2909mg (dp $1702 \mathrm{mg}$ ), com um consumo médio de 469 mg (dp $343 \mathrm{mg}$ ) no café da manhã fora do lar, 1500 mg (dp 944 mg) no almoço e 1358 mg (dp 1323 mg) no jantar. Enquanto o consumo diário médio de açúcar de adição foi de $43 \mathrm{~g}$ (dp 42g), com um consumo médio de $14 \mathrm{~g}$ (dp $21 \mathrm{~g}$ ) no café da manh, 21 g (dp 30 g) no almoço e 24 g (dp $32 \mathrm{~g})$ no jantar realizado fora do lar.

Tabela 1. Prevalência de alimentação fora do lar, razão de prevalência (RP) e intervalo de confiança em relação.

\begin{tabular}{|c|c|c|c|c|c|c|}
\hline \multirow[b]{2}{*}{ Variáveis } & \multirow[b]{2}{*}{$\mathrm{n}$} & \multirow[b]{2}{*}{$\%$} & \multicolumn{2}{|l|}{ Modelo bruto } & \multicolumn{2}{|c|}{ Modelo ajustado $^{\mathrm{a}}$} \\
\hline & & & RP (IC95\%) & $\mathrm{p}$ & RP (IC95\%) & $\mathrm{p}$ \\
\hline Sexo & & & & $0.548^{b}$ & & \\
\hline Masculino & 84 & $43 \%$ & 1 & & & \\
\hline Feminino & 112 & $57 \%$ & $1.11(0.77-1.61)$ & & & \\
\hline Idade & & & & $0.758^{c}$ & & \\
\hline 12-19 anos & 50 & $26 \%$ & 1 & & & \\
\hline 20-59 anos & 71 & $36 \%$ & $1.01(0.76-1.33)$ & & & \\
\hline 60 anos ou mais & 75 & $38 \%$ & $1.05(0.81-1.38)$ & & & \\
\hline Renda familiar per capita & & & & $0.211^{\mathrm{c}}$ & & \\
\hline Até dois salários mínimos & 142 & $76 \%$ & 1 & & & \\
\hline 3-6 salários mínimos & 20 & $10 \%$ & $1.54(0.98-2.40)$ & & & \\
\hline 6 ou mais salários mínimos & 26 & $14 \%$ & $0.79(0.18-3.41)$ & & & \\
\hline Tabagismo & & & & $0.015^{\mathrm{c}}$ & & $0.009^{c}$ \\
\hline Nunca & 143 & $73 \%$ & 1 & & 1 & \\
\hline Ex-fumante & 24 & $12 \%$ & $0.51(0.30-0.84)$ & & $0.47(0.28-0.78)$ & \\
\hline Fumante & 29 & $15 \%$ & $1.03(0.70-1.52)$ & & $0.89(0.61-1.31)$ & \\
\hline Etilismo & & & & $0.62^{b}$ & & \\
\hline Não & 115 & $59 \%$ & 1 & & & \\
\hline $\operatorname{sim}$ & 81 & $51 \%$ & $0.92(0.66-1.27)$ & & & \\
\hline Estado nutricional & & & & $0.106^{\mathrm{b}}$ & & $0.047^{\mathrm{c}}$ \\
\hline Sem sobrepeso & 19 & $10 \%$ & 1 & & 1 & \\
\hline Sobrepeso & 80 & $42 \%$ & $1.26(0.95-1.67)$ & & $1.33(1.01-1.77)$ & \\
\hline $\begin{array}{l}\text { a Modelo ajustado pelas var } \\
\text { b Teste qui-quadrado } \\
\text { c Teste de Wald } \\
* \text { p }<0.05\end{array}$ & de & & bagismo e estado & icion & & \\
\hline
\end{tabular}

As tabelas 3, 4, 5 e 6 apresentam os principais grupos de alimentos consumidos fora do lar contribuintes de energia, gordura total, sódio e açúcar de adição, respectivamente. $\mathrm{O}$ grupo das frutas foi relatado apenas em $6 \%$ das refeições $(0,5 \%$ café da manhã, $4 \%$ almoço e $1,5 \%$ jantar). 
Tabela 2. Frequência dos 15 principais grupos alimentares na alimentação fora do lar. São Paulo, 2010-2011.

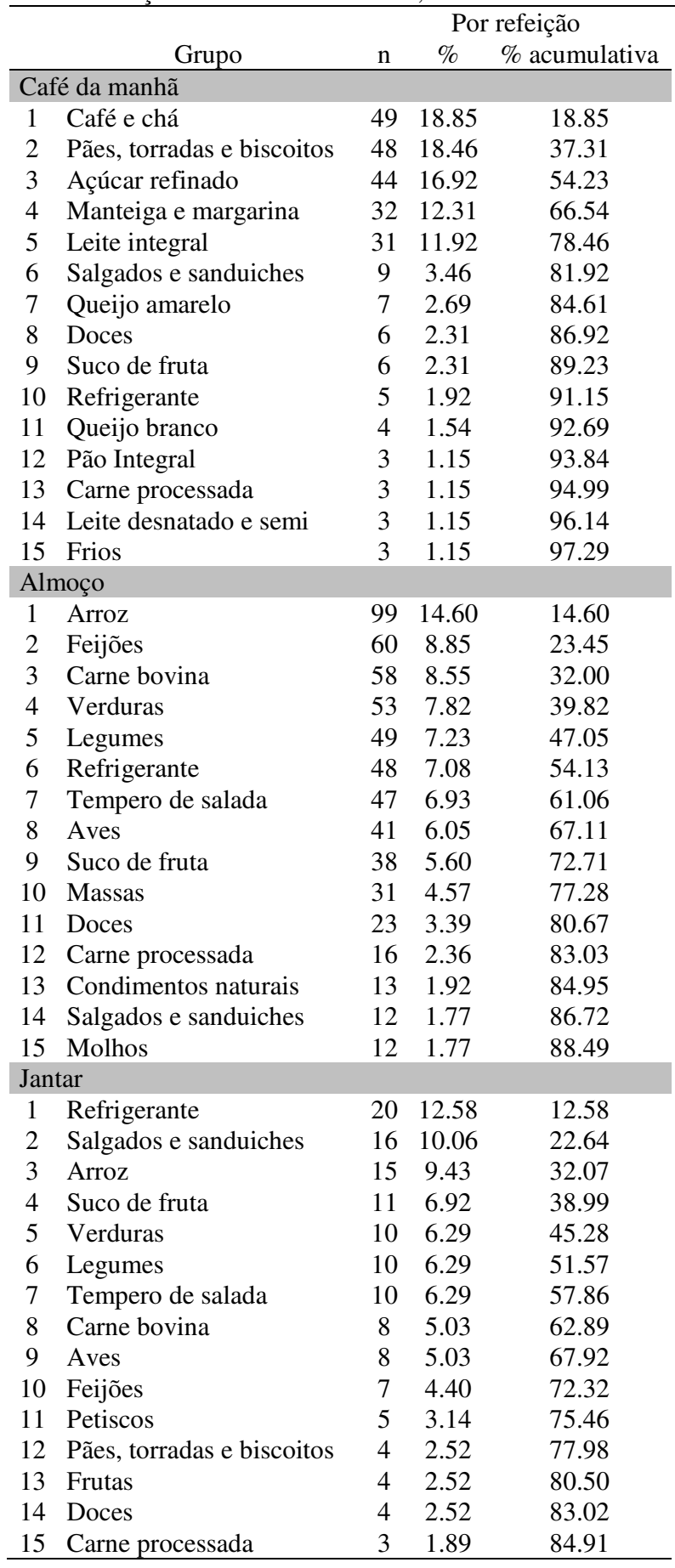


Tabela 3. Relação dos 15 principais grupos alimentares contribuintes em energia na alimentação fora do lar. São Paulo, 2010-2011.

\begin{tabular}{|c|c|c|c|}
\hline \multirow{2}{*}{\multicolumn{2}{|c|}{ Grupo }} & \multicolumn{2}{|c|}{$\begin{array}{c}\text { Por refeição } \\
\%\end{array}$} \\
\hline & & $\%$ & acumulativa \\
\hline \multicolumn{4}{|c|}{ Café da manhã } \\
\hline 1 & Pães, torradas e biscoitos & 38.27 & 38.27 \\
\hline 2 & Manteiga e margarina & 13.72 & 51.99 \\
\hline 3 & Leite integral & 9.13 & 61.12 \\
\hline 4 & Salgados e sanduiches & 7.51 & 68.63 \\
\hline 5 & Doces & 7.46 & 76.09 \\
\hline 6 & Açúcar refinado & 5.46 & 81.55 \\
\hline 7 & Refrigerante & 3.90 & 85.45 \\
\hline 8 & Queijo amarelo & 3.25 & 88.70 \\
\hline 9 & Suco de fruta & 2.79 & 91.49 \\
\hline 10 & Pão Integral & 2.14 & 93.63 \\
\hline 11 & Queijo branco & 1.96 & 95.59 \\
\hline 12 & Leite desnatado e semi & 0.95 & 96.54 \\
\hline 13 & Frios & 0.81 & 97.35 \\
\hline 14 & Carne processada & 0.71 & 98.06 \\
\hline 15 & Achocolatados & 0.61 & 98.67 \\
\hline \multicolumn{4}{|c|}{ Almoço } \\
\hline 1 & Arroz & 22.73 & 22.73 \\
\hline 2 & Carne bovina & 14.30 & 37.03 \\
\hline 3 & Massas & 8.92 & 45.95 \\
\hline 4 & Aves & 7.46 & 53.41 \\
\hline 5 & Refrigerante & 7.18 & 60.59 \\
\hline 6 & Doces & 7.03 & 67.62 \\
\hline 7 & Salgados e sanduiches & 5.61 & 73.23 \\
\hline 8 & Feijões & 5.28 & 78.51 \\
\hline 9 & Carne processada & 3.38 & 81.89 \\
\hline 10 & Bebida Alcoolica & 3.23 & 85.12 \\
\hline 11 & Petiscos & 2.98 & 88.10 \\
\hline 12 & Tempero salada & 2.08 & 90.18 \\
\hline 13 & Suco de fruta & 2.06 & 92.25 \\
\hline 14 & Carne suina & 1.27 & 93.51 \\
\hline 15 & Pães, torradas e biscoitos & 1.22 & 94.74 \\
\hline \multicolumn{4}{|c|}{ Jantar } \\
\hline & Salgados e sanduiches & 29.08 & 29.08 \\
\hline 2 & Arroz & 12.7 & 41.78 \\
\hline 3 & Carne bovina & 9.873 & 51.65 \\
\hline 4 & Refrigerante & 9.526 & 61.18 \\
\hline 5 & Aves & 8.06 & 69.24 \\
\hline 6 & Bebida alcoolica & 5.422 & 74.66 \\
\hline 7 & Petiscos & 4.365 & 79.03 \\
\hline 8 & Doces & 2.9 & 81.93 \\
\hline 9 & Suco de fruta & 2.521 & 84.45 \\
\hline & Carne suina & 2.306 & 86.76 \\
\hline & Pães, torradas e biscoitos & 2.175 & 88.93 \\
\hline & Feijões & 1.852 & 90.78 \\
\hline 13 & Carne processada & 1.672 & 92.45 \\
\hline & Frutas & 1.475 & 93.93 \\
\hline 15 & Massas & 1.311 & 95.24 \\
\hline
\end{tabular}


Tabela 4. Relação dos 15 principais grupos alimentares contribuintes de gorduras totais na alimentação fora do lar. São Paulo, 2010-2011.

\begin{tabular}{|c|c|c|c|}
\hline \multirow{2}{*}{\multicolumn{2}{|c|}{ Grupo }} & \multicolumn{2}{|c|}{$\begin{array}{c}\text { Por refeição } \\
\%\end{array}$} \\
\hline & & $\%$ & acumulativa \\
\hline \multicolumn{4}{|c|}{ Café da manhã } \\
\hline 1 & Manteiga e margarina & 41.05 & 41.05 \\
\hline 2 & Pães, torradas e biscoitos & 14.29 & 55.34 \\
\hline 3 & Leite integral & 13.10 & 68.45 \\
\hline 4 & Salgados e sanduiches & 9.83 & 78.28 \\
\hline 5 & Doces & 6.16 & 84.44 \\
\hline 6 & Queijo amarelo & 6.12 & 90.57 \\
\hline 7 & Queijo branco & 3.22 & 93.79 \\
\hline 8 & Frios & 1.93 & 95.72 \\
\hline 9 & Carne processada & 1.08 & 96.81 \\
\hline 10 & Ovos & 1.07 & 97.88 \\
\hline 11 & Pães integrais & 0.77 & 98.65 \\
\hline 12 & Leite desnatado e semi & 0.49 & 99.13 \\
\hline 13 & Lacteos & 0.40 & 99.54 \\
\hline 14 & Suco de fruta & 0.20 & 99.74 \\
\hline 15 & Café e chas & 0.11 & 99.85 \\
\hline \multicolumn{4}{|c|}{ Almoço } \\
\hline 1 & Carne bovina & 19.11 & 19.11 \\
\hline 2 & Arroz & 13.35 & 32.45 \\
\hline 3 & Salgados e sanduiches & 9.43 & 41.89 \\
\hline 4 & Doces & 9.12 & 51.00 \\
\hline 5 & Massas & 8.45 & 59.45 \\
\hline 6 & Aves & 8.30 & 67.75 \\
\hline 7 & Carne processada & 7.32 & 75.07 \\
\hline 8 & Tempero salada & 6.95 & 82.02 \\
\hline 9 & Petiscos & 4.59 & 86.61 \\
\hline 10 & Feijões & 2.88 & 89.49 \\
\hline 11 & Carne suina & 2.72 & 92.21 \\
\hline 12 & Ovos & 2.06 & 94.27 \\
\hline 13 & Molhos & 1.67 & 95.94 \\
\hline 14 & Queijo branco & 0.92 & 96.86 \\
\hline 15 & Queijo amarelo & 0.84 & 97.69 \\
\hline \multicolumn{4}{|c|}{ Jantar } \\
\hline 1 & Salgados e sanduiches & 40.01 & 40.01 \\
\hline 2 & Carne bovina & 13.79 & 53.80 \\
\hline 3 & Aves & 11.18 & 64.98 \\
\hline 4 & Arroz & 7.07 & 72.05 \\
\hline 5 & Petiscos & 6.35 & 78.40 \\
\hline 6 & Carne suina & 4.19 & 82.58 \\
\hline 7 & Tempero salada & 3.90 & 86.48 \\
\hline 8 & Carne processada & 3.22 & 89.70 \\
\hline 9 & Manteiga e margarina & 1.78 & 91.48 \\
\hline 10 & Massas & 1.56 & 93.04 \\
\hline 11 & Queijo amarelo & 1.30 & 94.34 \\
\hline 12 & Ovos & 1.26 & 95.60 \\
\hline 13 & Doces & 1.13 & 96.73 \\
\hline 14 & Feijões & 0.96 & 97.69 \\
\hline 15 & Leite integral & 0.61 & 98.30 \\
\hline
\end{tabular}


Tabela 5. Relação dos 15 principais grupos alimentares contribuintes de sódio na alimentação fora do lar. São Paulo, 2010-2011.

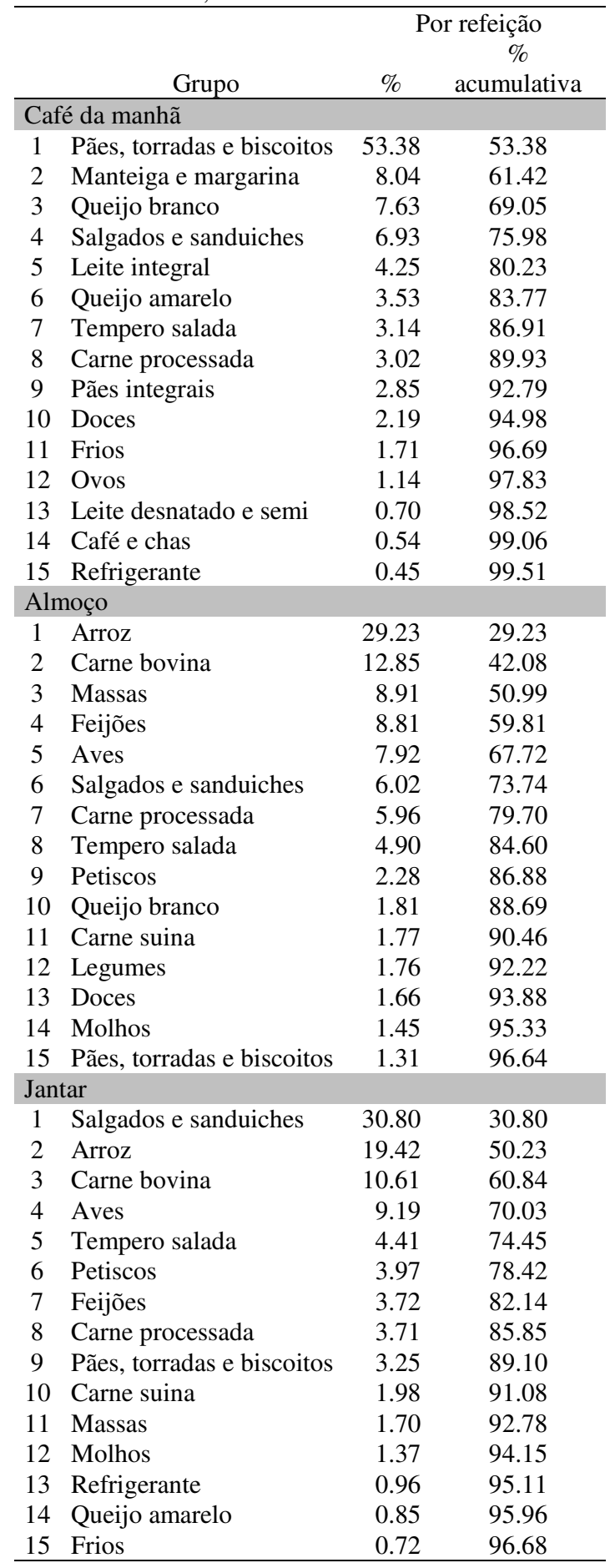


Tabela 6. Contribuição dos grupos alimentares no consumo de açúcar de adição na alimentação fora do lar. São Paulo, 2010-2011.

\begin{tabular}{crcc}
\hline \multicolumn{1}{c}{ Grupo } & \multicolumn{2}{c}{$\begin{array}{c}\text { Por refeção } \\
\%\end{array}$} \\
\multicolumn{1}{c}{$\begin{array}{c}\text { \% } \\
\text { acumulativa }\end{array}$} \\
\hline Café da manhã & & \\
1 & Açúcar refinado & 28.97 & 28.97 \\
2 & Refrigerante & 23.32 & 52.29 \\
3 & Doces & 21.77 & 74.06 \\
4 & Pães, torradas e biscoitos & 14.57 & 88.62 \\
5 & Suco de fruta & 4.74 & 93.36 \\
6 & Achocolatado & 2.76 & 96.12 \\
7 & Salgados e sanduiches & 1.60 & 97.72 \\
8 & Pães integrais & 1.36 & 99.08 \\
9 & Lacteos & 0.72 & 99.80 \\
10 & Frios & 0.17 & 99.97 \\
11 & Carne processada & 0.03 & 100.00 \\
Almoço & & \\
1 & Refrigerante & 63.06 & 63.06 \\
2 & Doces & 22.23 & 85.29 \\
3 & Suco de fruta & 4.28 & 89.58 \\
4 & Açúcar refinado & 3.27 & 92.85 \\
5 & Bebida alcoolica & 2.82 & 95.67 \\
6 & Massas & 1.87 & 97.54 \\
7 & Salgados e sanduiches & 1.45 & 98.99 \\
8 & Carne processada & 0.60 & 99.59 \\
9 & Pães, torradas e biscoitos & 0.20 & 99.79 \\
10 & Molhos & 0.14 & 99.93 \\
11 & Carne suina & 0.05 & 99.98 \\
12 & Frios & 0.01 & 100.00 \\
Jantar & & \\
1 & Refrigerante & 68.28 & 68.28 \\
2 & Doces & 14.66 & 82.94 \\
3 & Suco de fruta & 5.22 & 88.16 \\
4 & Salgados e sanduiches & 4.70 & 92.86 \\
5 & Bebida alcoolica & 3.51 & 96.37 \\
6 & Açúcar refinado & 2.17 & 98.54 \\
7 & Molhos & 0.76 & 99.30 \\
8 & Pães, torradas e biscoitos & 0.50 & 99.80 \\
9 & Carne processada & 0.09 & 99.90 \\
11 & Frios & Massas & 99.96 \\
\hline & & 100.00 \\
\hline
\end{tabular}

\section{Discussão}

Neste estudo, conduzido com o objetivo de caracterizar as refeições realizadas fora do lar, identificando a proporção das refeições (café da manhã, almoço e jantar), e a 
contribuição dos alimentos que as compõem para o consumo diário de energia, gordura, sódio e açúcar de adição, verificou-se elevada frequência de alimentos convencionais, típicos do hábito alimentar brasileiro, como café, pães, açúcar refinado, manteiga e margarina, e leite integral no café da manhã, e arroz; feijões; carne bovina; verduras; legumes no almoço. ${ }^{16}$ No jantar, por sua vez, houve predomínio dos grupos de alimentos ricos em açúcar, gordura e sódio, como refrigerantes, salgados, sanduíches e pizza que, somados aos grupos de alimentos manteiga e margarina; pães, torradas e biscoitos; e leite integral (consumidos no café da manhã) e carne bovina e arroz (consumidos no almoço e jantar) lideram a contribuição das gorduras totais na alimentação fora do lar.

A identificação do arroz como um dos principais contribuintes de energia, gordura total e sódio, pode ser justificável não só pelo fato de ser tradicional e frequente nas refeições dos brasileiros, mas também pelo hábito de refogar e adicionar sal em seu preparo. Amorim et al. ${ }^{17}$, ao quantificar o teor de gordura consumido no almoço self service de uma empresa, constataram que a quantidade de óleo adicionada ao preparo de uma porção de arroz (108g) variou de 1,37 ml a 4,18 ml, enquanto o recomendado varia entre $1,5 \mathrm{ml}$ a 2,0 $\mathrm{ml}$, e ressaltaram ainda que a quantidade de óleo utilizada para refogar o arroz correspondeu a 11\% do total calórico médio da preparação.

Os alimentos prontos e rápidos para o consumo, usualmente chamados de fastfood, como salgados, sanduiches e pizzas, que tiveram participação importante no jantar, tem como característica um custo relativamente baixo, o que pode contribuir para o seu consumo. ${ }^{18}$ Alimentos com alta densidade energética, habitualmente ricos em gorduras e pobres em nutrientes, são os que possuem menores preços, enquanto alimentos de baixa densidade energética costumam ser mais caros e com maior variação de preço. ${ }^{18-19}$ A POF 2008/09 mostra que cerca de 40 a $60 \%$ da energia provenientes das bebidas alcoólicas, refrigerantes, salgados, sanduiches e pizzas são consumidas fora do lar. ${ }^{20}$ Embora estudos brasileiros não comparem o teor de sódio de refeições consumidas dentro e fora do domicílio, estudo realizado em 2002 no Estados Unidos, ao comparar 
as características das refeições preparadas dentro e fora do domicílio, mostrou que refeições preparadas fora do domicílio apresentavam maior teor energético e sódio de adição (desconsiderando saleiros de mesa) que as refeições preparadas no domicílio. ${ }^{21}$

O baixo consumo de frutas também foi encontrado por Bigio et al. $(2011)^{22}$, no qual apenas 6\% dos adolescentes de 12 a 19 anos do município de São Paulo consumiram ao longo do dia quantidades de frutas, verduras e legumes iguais ou superiores à recomendação de 400 gramas/dia e que $22 \%$ não consumiram nenhum tipo de fruta, verdura ou legume no dia avaliado. Dados representativos nacionais revelam um consumo médio diário de $54 \mathrm{kcal}$ oriundos de frutas, valor inferior a uma porção (70kcal). Sendo cerca de $16 \%$ consumidos fora do lar. ${ }^{20}$ Esses dados sugerem que a ausência de frutas na alimentação seja um possível hábito alimentar da população paulistana, independente de alimentar-se dentro ou fora de casa. A contribuição das frutas e do suco de frutas no consumo de gorduras totais fora do lar se deve, em maior parte, pelo consumo de abacate, açaí e coco.

Como principais contribuintes de açúcar de adição nas refeições fora do lar, além do açúcar refinado no café da manhã, aparecem os refrigerantes e doces. Este resultado mostra-se semelhante ao encontrado por Bezerra e Sichieri em $2002^{23}$, que identificaram os refrigerantes como o grupo de alimentos mais consumido fora do domicilio pela população brasileira. Apesar de analisar as características da alimentação fora do lar, o estudo não considerou as quantidades consumidas e a contribuição energética e de nutrientes dessa alimentação, atentando-se apenas às frequências de consumo. Lobato et al. (2009) $)^{24}$, utilizando dados da POF 2002/03, encontraram associação positiva e significante entre o consumo de refrigerantes e obesidade entre as mulheres.

Dentre os poucos estudos nacionais publicados sobre alimentação fora do lar de populações, grande parte não considera cada refeição separadamente, agrupando todos os alimentos consumidos no almoço e jantar em um único grupo, usualmente 
denominado "refeições", o que impede um maior detalhamento dos tipos e das quantidades de alimentos consumidos em cada refeição realizada fora do lar. Não há na literatura consenso na definição de alimentação fora do lar, alguns autores definem pelo local de consumo, independente do local de preparo, ${ }^{25-27}$ enquanto outros consideram o local de preparo, independente do local de consumo. ${ }^{1,28-30}$ No entanto é possível que alguns alimentos sejam preparados em casa e consumidos na escola ou trabalho e outros alimentos sejam comprados em restaurantes ou lanchonetes e consumidos em casa. Essa diferença nas definições e a falta de estudos que as combinem dificulta a comparação dos achados.

A relação encontrada no modelo múltiplo entre comer fora de casa e ter sobrepeso reforça a hipótese de que realizar refeições fora de casa seja um possível fator de risco para a obesidade. ${ }^{31-34}$ Além disso, a associação observada nos modelos univariado e múltiplo entre a alimentação fora do lar e ser ex-fumante pode estar relacionada ao motivo pelo qual os indivíduos resolveram parar de fumar. Essas pessoas possivelmente apresentam atualmente uma maior preocupação com a saúde. Estudos mostram que ex-fumantes alimentam-se mais de frutas, verduras e legumes e consomem menor quantidade de refrigerantes quando comparados aos fumantes e nunca fumantes. ${ }^{35-36}$

Dentre as limitações deste estudo podemos citar a análise de um único dia da dieta, não caracterizando, portanto uma análise baseada no consumo alimentar usual. Porém, o consumo médio de um grupo de indivíduos pode ser obtido se forem contempladas todas as estações do ano e todos os dias da semana durante a aplicação do inquérito, o que ocorreu neste estudo. ${ }^{37}$ Outra limitação foi não distinguir as refeições feitas em restaurantes das realizadas em lanchonetes, como os fast-foods, por exemplo. No Brasil, o consumo de refeições "sit-down-meals", servidas na mesa, é mais frequente que fast-food, e associam-se positivamente ao sobrepeso e obesidade em homens, porem, entre as mulheres, revela-se um fator de proteção, sugerindo que as 
brasileiras fazem escolhas mais saudáveis quando se alimentam fora do domicilio. ${ }^{38}$

Os dados apresentados estimam o consumo de alimentos por refeições realizadas fora do lar. Analisar o consumo alimentar por refeições permite uma melhor caracterização da alimentação, auxiliando na identificação de hábitos alimentares diversos, como os encontrados nas principais refeições (almoço e jantar) analisadas neste estudo. Os achados sugerem padrões alimentares distintos em cada uma das três principais refeições. Pôde-se observar a presença tanto de alimentos marcadores de uma dieta saudável, a exemplo do arroz e feijão, como de alimentos integrantes de uma dieta não saudável como refrigerantes, salgados, sanduíches e pizzas. No entanto, ainda são escassas, principalmente em âmbito nacional, pesquisas que comparem o consumo alimentar de uma mesma população por local de consumo e observem se de fato há diferenças nos padrões alimentares, ou se, quando fora de casa, há apenas reflexos de hábitos alimentares praticados dentro de casa.

Devido à escassez de dados relativos ao consumo alimentar fora do lar, em especial das características das refeições, e a complexidade da escolha alimentar, faz-se necessário um maior aprofundamento no estudo dos determinantes destas escolhas, possibilitando, assim, um melhor entendimento das suas repercussões na saúde e possíveis políticas de educação e prevenção, incluindo pesquisas acerca das influências dos fatores ambientais nas escolhas alimentares.

\section{Colaboradores}

B. M. Gorgulho, R. M. Fisberg e D. M. L. Marchioni participaram do planejamento do artigo, coleta e análise dos dados, bem como da redação do manuscrito.

\section{Agradecimentos}

O Inquérito de Saúde de São Paulo é uma parceria entre a Faculdade de Saúde 
Pública da Universidade de São Paulo e a Secretaria municipal de Saúde de São Paulo. Com financiamento da Fundação de Amparo a Pesquisa do Estado de São Paulo e do Conselho Nacional de Desenvolvimento Científico e Tecnológico.

\section{Referências}

1. Lin B, Frazão E, Guthrie J. Away-from-home foods increasingly important to quality of American diet. Washington DC: Food and Rural Economics Division, Economic Research Service; 1999. (U.S. Department of Agriculture Information Bulletin, 749).

2. Kearney JM, Hulshof KFAM, Gibney MJ. Eating patterns temporal distribution, converging and diverging foods, meals eaten inside and outside of the home implications for developing FBDG. Public Health Nutr 2001; 4:693-8.

3. Bes-Rastrollo M, Basterra-Gortari FJ, Sánchez-Villegas A, Marti A, Martinez JA, Martinez-Gonzales MA. A prospective study of eating away-from-home meals and weight gain in a Mediterranean population: the SUN (Seguimiento Universidad de Navarra) cohort. Public Health Nutr 2010;13(9):1356-1363.

4. Kant AK, Graubard BI. Eating out in America, 1987- 2000: trends and nutritional correlates. Prev Med 2004; 38:243-9. 19.

5. Abreu ES, Garbelotti ML, Torres EAFS. Dietary fiber consumption and composition foods in "by-the-kilo" restaurants. Nutr Food Science 2005; 35(6):386-392.

6. Ziegler P, Briefel R, Ponza M, Novak T, Hendricks K. Nutrient intakes and food patterns of toddlers' lunches and snacks: influences of location. J Am Dietetic Assoc 2006; 106(1S):124-34.

7. Department of Health and Human Services, National Heart Lung and Blood Institute. Working Group Report on Future Research Directions in Childhood Obesity Prevention and Treatment . Washington, DC: US Department of Health and Human Services; 2007.

8. Instituto Brasileiro de Geografia e Estatística - IBGE. Pesquisa de Orçamentos 
Familiares: Análise do consumo alimentar pessoal no Brasil. Rio de Janeiro; 2011. [acesso em 24 de julho 2012]. Disponível em <URL: http://www.ibge.gov.br/home/presidencia/noticias/noticia_visualiza.php?id_noti cia $=1648 \&$ id_pagina $=1>$.

9. Associação Brasileira das Empresas de Refeições Coletivas - ABERC. Mercado real de refeições. São Paulo, 2011 [Acesso em 24 de julho de 2012]. Disponível em < URL http://www.aberc.com.br/base.asp?id=3>.

10. Ministério da Saúde. Guia alimentar para a população brasileira: promovendo a alimentação saudável. Brasília, DF; 2006.

11. Site do Isa. Inquéritos de Saúde. Inquéritos de Saúde no município de São Paulo - ISA. São Paulo 2011[Acesso em 05 de novembro de 2012]. Disponível em < URL http://www.fsp.usp.br/isa-sp/ >.

12. Moshfegh AJ, Rhodes DG, Baer DJ, Murayi T, Clemens JC, Rumpler WV, Paul DR, Sebastian RS, Kuczynski KJ, Ingwersen LA, Staples RC, Cleveland LE. The US Department of Agriculture Automated Multiple-Pass Method reduces bias i n the collection of energy intakes. Am J Clin Nutr. 2008;88:324-332.

13. Nutrition Coordinating Center: Division of Epidemiology Nutrition Data System (NDS). Nutrition Data System for Research (NDS-R), ed. Minnesota: University of Minnesota; 1998.

14. Block G, Dresser CM, Hartman AM, Caroll MD. Nutrient sources in the American diet: quantitative data from the NHANES II survey. I. Vitamins and minerals. Am J Epidemiol. 1985; 122(1):13-26.

15. StataCorp. Stata Statistical Software: Release 10. College Station, TX: StataCorp LP 2007.

16. Barbosa L. Feijão com arroz e arroz com feijão: o Brasil no prato dos brasileiros. Horizontes antropológicos, Porto Alegre. 2007: 13(28);87-116.

17. Amorim MMA, Junqueira RG, Jokl L. Consumo de óleo e gordura nas preparações do almoço self service. Alim. Nutr., Araraquara. 2010: 21(2); 217223. 
18. United States Departament of Agriculture. Healthy, low calorie foods cost more on average. National Research Initiative. Estados Unidos, 2008 [Acesso em 24 de julho de 2012]. Disponível em $<$ URL http://www.csrees.usda.gov/newsroom/impact/2008/nri/pdf/price_of_food.pdf>.

19. Monsivais P, Drewnowski A. The rising cost of low-energy-density foods. J Am Diet Assoc. 2007;107(12):2071-6.

20. Bezerra IN, Souza AM, Pereira RA, Sichieri R. Contribution of foods consumed away from home to energy intake in Brazilian urban áreas: the 2008-9 Nationwide Dietary Survey. Br J Nutr 2012. Doi: 10.1017/S0007114512003169.

21. Guthrie JF, Lin B, Frazao E. Role of food prepared away from home in the american diet, 1977-78 versus 1994-96: changes and consequences. J Nutr Educ Behav. 2002;34(3):140-50.

22. Bigio RS, Verly Jr E, Castro MA de, Cesar CLG, Fisberg RM, Marchioni DML. Determinantes do consumo de frutas e hortaliças em adolescentes por regressão quantílica. Rev Saúde Pública. 2011;45(3):448-456.

23. Bezerra IN, Sichieri R. Características e gastos com alimentação fora do domicílio no Brasil. Rev Saúde Públ. 2010;44(2):221-29.

24. Lobato JCP, Costa AJL, Sichieri R. Food Intake and prevalence of obesity in Brazil: an ecological analysis. Public Health Nutrition, 2009; 12(11):2209-2215.

25. Gregory J, Foster K, Tyler H, Wiseman M. The Dietary and Nutritional Survey of British Adults. London: HMSO, 1990; 218-27.

26. Kearney JM, Hulshof KFAM, Gibney MJ. Eating patterns - temporal distribution, converging and diverging foods, meals eaten inside and outside of the home - implications for developing FBDG. Public Health Nutrition 2001; 4(2B): 693-8.

27. Orfanos P, Naska A, Trichopoulos D, et al. Eating out of home and its correlates in 10 European countries. The European Prospective Investigation into Cancer and Nutrition (EPIC) study. Public Health Nutr 2007;10:1515-1525.

28. Guilkey DK, Haines PS, Popkin BM. The distribution of food consumption over 
a year: a longitudinal analysis. Am. J. Agric. Econ. 1990; 72: 891-900.

29. Horton S, Campbell C. Wife's employment, food expenditure and apparent nutrient intake: evidence from Canada. Am. J. Agric. Econ. 1991; 73: 784-94.

30. Burns C, Jackson M, Gibbons C, Stoney RM. Foods prepared outside the home: association with selected nutrients and body mass index in adult Australians. Pub Health Nutr 2002;5:441-48.

31. BT. Fast food consumption of US adults: impact on energy and nutrient intakes and overweight status. J Am Coll Nutr 2004;23:163-168.

32. Satia JA, Galanko JA, Siega-Riz AM. Eating at fast-food restaurants is associated with dietary intake, demographic, psychosocial and behavioural factors among African Americans in North Carolina. Public Health Nutr 2004;7:1089-1096.

33. Schmidt M, Affenito SG, Striegel-Moore R, Khoury PR, Barton B, Crawford P, Kronsberg S, Schreiber G, Obarzanek E, Daniels S. Fast-food intake and diet quality in black and white girls: the National Heart, Lung, and Blood Institute Growth and Health Study. Arch Pediatr Adolesc Med 2005;159:626-631.

34. Befort C, Kaur H, Nollen N, Sullivan DK, Nazir N, Choi WS, Hornberger L, Ahluwalia JS. Fruit, vegetable, and fat intake among non-Hispanic black and non-Hispanic white adolescents: associations with home availability and food consumption settings. J Am Diet Assoc 2006;106:367-373.

35. Neutzling MB, et al . Fatores associados ao consumo de frutas, legumes e verduras em adultos de uma cidade no Sul do Brasil. Cad Saúde Pública. 2009;25(11):2365-74.

36. Rombaldi AJ, Neutzling MB, Silva MC, Azevedo MR, Hallal PC. Fatores associados ao consumo de refrigerante não dietético em adultos de pelotas, RS. Rev Saude Publ 2011; 45(2):382-390.

37. Miller PE, Mitchell DC, Harala PL, Pettit JM, Smiciklas-Wright H, Hartman TJ. Development and evaluation of a method for calculating the Healthy Eating Index-2005 using the Nutrition Data System for Research. Public health 
nutrition. 2011;14(2):306-13.

38. Bezerra NI, Sichieri R. Eating out of home and obesity: a Brazilian nationwide survey. Public Health Nutrition 2009; 12(11):2037-43.

\title{
5.2. Artigo 2
}

Nutritional quality of meals consumed away from home and its association with the overall diet quality

Bartira M. Gorgulho, Regina M. Fisberg e Dirce Maria L. Marchioni

Artigo será submetido à revista Preventive Medicine

\begin{abstract}
Objective. To evaluate the nutritional quality of meals consumed away from home and its association with overall diet quality. Method. Data obtained from 834 participants of a Health Survey in São Paulo, Brazil. Food intake was measured by a 24-hour dietary recall applied telephonically using the Automated Multiple-Pass Method. Overall dietary quality was assessed by the Brazilian Healthy Eating Index Revised (B-HEIR) and the Meal Quality Index (MQI) was used to evaluate dietary quality of the main meals. The association between the B-HEIR and the MQI was assessed by linear regression analysis. Results. The consumption of at least one of the three main meals away from home was reported for, $32 \%$ of respondents (70 adolescents, 156 adults and 40 elderly). The average MQI score of lunch, consumed away from home, was lower than lunch consumed at home, with higher amounts of total and saturated fats. The average score of B-HEIR was 58 points and was associated with the MQI score,
\end{abstract}


energy, meal consumption location and gender. Conclusion. Lunch consumed away from home presented the worst quality, being higher in total and satured fat. However, the meals consumed at home also need improvement.

Keywords: Food habits; Diet; Food consumption away from home

\section{Introduction}

Once considered a problem only in high income countries, overweight and obesity are now sharply on the rise in low and middle income countries, particularly in urban settings (Popkin, 2001). Modern societies seem to be converging on a diet high in saturated fats, sugar, and refined products and low in fiber rich-foods (Popkin, 2004).

The increased food consumption away from home has been pointed as one of the causes for the obesity epidemic (Abreu et al, 2005; Bes-Rastrollo et al, 2010; Lin et al, 1999; Kant \& Graubard, 2004; Kearney et al, 2001; Ziegler et al, 2006). In Brazil, for example, the food service market grew from 7.5 million meals served in 1998, to 16.5 million meals served in 2011 (ABERC, 2012). Some cross-sectional and longitudinal studies have shown association between food consumption away from home and the frequency of eating out, and weight gain (Befort et al, 2006; Satia et al, 2004; Schmidt et al, 2005). The high energy density of foods eaten away from home is a possible explanation for this association (Schroder et al, 2007).

While previous studies have suggested a negative influence of away from home food consumption on obesity among all age groups, no previous research has explored the direct effect of the quality of meals consumed away from home on the quality of dietary intake. Considering that, diet is a modifiable risk factor for chronic diseases and the growing number of people who eat away from home, the objective of this study was to evaluate the quality of meals consumed away from home and its association with the overall diet quality. 


\section{Methods}

Data were obtained from a cross-sectional population-based survey on health and living conditions with a representative sample of adolescents, adults and elderly people living in the city of São Paulo, southeastern Brazil, in 2008 ( Inquéritos de Saúde de São Paulo - ISA).

The present study used data on 834 residents of the city of São Paulo, of which 232 were adolescents aged between 12 and 19 years, 304 were adults aged between 20 and 59, and 298 were elderly with 60 years or more, from both genders. .

Food intake was measured by a 24-hour dietary recall applied telephonically using the Nutrition Data System for Research, software developed at the University of Minnesota for gathering nutritional information, which incorporates the Automated Multiple-Pass Method. The primary source of nutritional food values was the US Department of Agriculture (USDA) nutritional composition table, and this was extended with information provided by food manufacturers, the scientific literature and other published food tables. The Automated Multiple-Pass Method is a 5-step dietary interview that helps individuals to recall foods and beverages consumed on the day before the interview and to record them in detail, thus reducing dietary measurement errors (Moshfegh et al, 2008).

The overall dietary quality was assessed by the Brazilian Healthy Eating Index Revised (B-HEIR) (Previdelli et al, 2011). The B-HEIR components were primarily based on Dietary Guidelines for Brazilians (MS, 2006) and expressed on a density basis $(1000 \mathrm{kcal} / \mathrm{g})$. Intakes at the standard level or higher were assigned the maximum number of total points: 5 points (Total Grains; Whole Grains; Dark-Green and Orange Vegetables and Beans (GOV-B); Total Vegetables; Total Fruit and Whole Fruit); 10 points (Dairy Products; Meat and Beans; Oils; Saturated Fat; and Sodium) and 20 points 
for SoFAAS (total calories from solid fat, alcohol and added sugar) (Previdelli et al, 2011).

For the current analysis, away from home eating was defined as those 309 foods reportedly consumed while they were not at home, irrespective of place of production. For example, snacks prepared at home and consumed at work were considered away from home eating. This definition has been previously used (Orfanos et al, 2007).

The Meal Quality Index (MQI) was used to evaluate dietary quality of the main meals, i.e., breakfast, lunch and dinner, (Bandoni \& Jaime, 2008). It is composed of five components, with scores ranging from 0 to 20 points, based on the World Health Organization's recommendations (WHO, 2003) and in the Dietary Guide for the Brazilian Population (MS, 2006). Intermediate values were scored proportionally. The MQI components are described below.

\section{Adequacy of the availability of vegetables and fruit}

This item enabled verification of the adequacy of the offered amounts of this food group (in grams per meal). Since the daily recommended intake is $400 \mathrm{~g} / \mathrm{day}$, equivalent to five portions per day, it is expected that a large meal would provide at least two portions, i.e. availability of $160 \mathrm{~g}$. This amount was scored as 20, while availability of less than $80 \mathrm{~g}$ received a score of 0 .

\section{Carbohydrate availability}

This item was expressed as the percentage of carbohydrate availability (kcal) in relation to energy. Total carbohydrates should, ideally, provide between $55 \%$ to $75 \%$ of total energy intake. Meals whose carbohydrate availability were within this range received a score of 20 , while meals whose availability were less than $40 \%$ received a score of 0 .

\section{Total fat availability}


Between $15 \%$ to $30 \%$ of total energy intake is recommended to be derived from fat. Meals with energy provided by fat, that were within this range, were scored as 20 , while those with total fat availability greater than $40 \%$ received a score of 0 .

\section{Saturated fat availability}

Total energy availability coming from saturated fatty acids, less than $10 \%$ was scored as 20 , while availability greater than $13 \%$ received a score of 0 .

\section{Menu variability}

Menu variability took into account the number of different foods (score ranging from 0 to 14 points, where 14 was scored for 11 or more different types of foods and 0 was scored for fewer than five different foods) and the number of food groups (score ranging from 0 to 6 points, where 6 was scored for menus with at least five different groups and 0 was scored for fewer than three different food groups). For foods to be taken into account, at least half a portion should be consumed, except for foods in the sugar and sweets group, oils and fats group and the miscellanea group (coffee, tea and salt, among others), which was not included in this index. At the end of this stage, the two scores were summed, to establish the variety index on a scale ranging from 0 to 20 points.

The association between the B-HEIR and the meals consumed away from home was assessed by linear regression analysis (stepwise forward selection), once the BHEIR had a normal distribution. The dependent variable was the overall dietary quality (B-HEIR) and the independent variables were the meal consumed away from home ( breakfast, lunch or dinner), meal location (inside or away from home), gender (male or female), household income per capita (tertile), age group (adolescent, adult or elderly) and nutritional status (overweight or not).

The analyses were performed using "survey" module of STATA and the significance level was $5 \%$. The project was approved by the Research Ethics Committee 
of the School of Public Health, University of São Paulo.

\section{Results}

Among the 834 respondents, 32\% (70 adolescents, 156 adults and 40 elderly) reported consumption of at least one of the three main meals (breakfast, lunch and dinner) outside home.

Table 1. Analysis on the scores for items in the Meal Quality Index. São Paulo, SP. 2010.

\begin{tabular}{|c|c|c|c|c|c|c|c|c|c|}
\hline & \multirow[b]{2}{*}{ Median } & \multirow[b]{2}{*}{ Mean } & \multicolumn{2}{|c|}{ Inside Home } & \multicolumn{5}{|c|}{ Away from Home } \\
\hline & & & $\mathrm{SEM}^{\mathrm{a}}$ & IC & Median & Mean & SEM $^{\mathrm{a}}$ & IC & $\mathrm{p}$ value* \\
\hline \multicolumn{10}{|l|}{ Breakfast } \\
\hline Fruit, greens and vegetable availability & 0.00 & 3.53 & 0.38 & $2.78 ; 4.28$ & 0.00 & 3.54 & 0.92 & $1.71 ; 5.38$ & 0.878 \\
\hline Carbohydrate availability & 17.03 & 13.37 & 0.38 & $12.62 ; 14.12$ & 16.96 & 14.06 & 1.00 & $12.06 ; 16.06$ & 0.650 \\
\hline Total fat availability & 12.33 & 10.42 & 0.47 & $9.49 ; 11.35$ & 14.15 & 11.67 & 1.18 & $9.31 ; 14.04$ & 0.670 \\
\hline Saturation fat availability & 0.18 & 8.53 & 0.48 & $7.59 ; 9.47$ & 0.00 & 7.26 & 1.26 & $4.75 ; 9.77$ & 0.800 \\
\hline Variability of the menu & 0.00 & 3.24 & 0.27 & $2.70 ; 3.77$ & 0.00 & 6.08 & 1.00 & $4.08 ; 8.09$ & $<0.001^{*}$ \\
\hline MQI & 40.00 & 39.09 & 1.21 & $36.72 ; 41.48$ & 40.42 & 42.62 & 3.24 & $36.17 ; 49.07$ & 0.300 \\
\hline \multicolumn{10}{|l|}{ Lunch } \\
\hline Fruit, greens and vegetable availability & 0.00 & 3.82 & 0.39 & $3.05 ; 4.59$ & 0.00 & 3.03 & 0.70 & $1.64 ; 4.41$ & 0.190 \\
\hline Carbohydrate availability & 11.95 & 10.43 & 0.44 & $9.57 ; 11.29$ & 10.58 & 9.09 & 0.85 & $7.41 ; 10.78$ & 0.270 \\
\hline Total fat availability & 20.00 & 14.51 & 0.43 & $13.67 ; 15.34$ & 20.00 & 12.19 & 0.95 & $10.32 ; 14.06$ & $0.009 *$ \\
\hline Saturation fat availability & 20.00 & 17.21 & 0.34 & $16.54 ; 17.88$ & 20.00 & 14.27 & 0.85 & $12.59 ; 15.96$ & $<0.001 *$ \\
\hline Variability of the menu & 0.00 & 2.99 & 0.28 & $2.45 ; 3.54$ & 0.00 & 3.96 & 0.58 & $2.82 ; 5.10$ & 0.051 \\
\hline MQI & 54.78 & 48.96 & 1.15 & $46.69 ; 51.23$ & 50.21 & 42.54 & 2.42 & $37.75 ; 47.34$ & $0.008^{*}$ \\
\hline \multicolumn{10}{|l|}{ Dinner } \\
\hline Fruit, greens and vegetable availability & 0.00 & 3.08 & 0.37 & $2.35 ; 3.82$ & 0.00 & 0.96 & 0.60 & $-0.25 ; 2.17$ & 0.106 \\
\hline Carbohydrate availability & 13.21 & 10.74 & 0.48 & $9.79 ; 11.67$ & 10.21 & 11.42 & 1.33 & $8.75 ; 14.09$ & 0.551 \\
\hline Total fat availability & 20.00 & 14.28 & 0.44 & $13.42 ; 15.14$ & 19.85 & 14.42 & 1.23 & $11.94 ; 16.89$ & 0.217 \\
\hline Saturation fat availability & 20.00 & 15.39 & 0.45 & $14.52 ; 16.27$ & 20.00 & 13.71 & 1.58 & $10.53 ; 16.89$ & 0.253 \\
\hline Variability of the menu & 0.00 & 2.72 & 0.25 & $2.23 ; 3.21$ & 0.00 & 2.41 & 0.79 & $0.81 ; 4.00$ & 0.896 \\
\hline MQI & 52.19 & 46.22 & 1.19 & $43.87 ; 48.57$ & 44.16 & 42.92 & 3.20 & $36.47 ; 49.38$ & 0.106 \\
\hline
\end{tabular}

The comparison between at home and away from home meal quality is presented in Table 1. There was a statistically significant difference on the average score for 
lunch, when the meal is consumed away from home. However, the breakfast consumed at home had lesser variability of food groups $(\mathrm{p}<0.001)$.

The average score of the B-HEIR was 58.29 (IC 95\%: 57.08-59.49; interquartile range: 50.48-68.24) points, corresponding to a diet that needs improvement in its quality.

Table 2. Mean score of B-HEIR for the controls variables and the linear regress model. São Paulo, SP. 2010.

\begin{tabular}{|c|c|c|c|c|c|c|c|}
\hline \multirow[b]{2}{*}{ Variáveis } & \multicolumn{2}{|c|}{ B-HEIR } & \multicolumn{2}{|c|}{ Bivariate Model } & \multicolumn{2}{|c|}{ Multiple Model $^{\mathrm{a}}$} & \multirow[b]{2}{*}{$\mathrm{p}$ tend $^{\mathrm{c}}$} \\
\hline & Mean & IC $(95 \%)$ & $\beta$ & $\mathrm{p}^{\mathrm{b}}$ & $\beta$ & $\mathrm{p}^{\mathrm{b}}$ & \\
\hline \multicolumn{8}{|l|}{ Meal consumed away from home } \\
\hline No & _ & _ & 1 & _ & 1 & _ & $0.020^{*}$ \\
\hline Breakfast & 54.62 & $51.99 ; 57.24$ & -2.32 & 0.558 & -2.97 & 0.468 & \\
\hline Lunch & 56.09 & $54.33 ; 57.85$ & -5.59 & $0.023 *$ & -5.71 & $0.027 *$ & \\
\hline Dinner & 53.44 & $50.36 ; 56.52$ & -8.33 & 0.07 & -8.22 & 0.087 & \\
\hline \multicolumn{8}{|l|}{ Sex } \\
\hline Male & 56.04 & $54.48 ; 57.59$ & 1 & _ & 1 & _ & 0.155 \\
\hline Female & 58.13 & $56.79 ; 59.46$ & 1.91 & $0.066^{*}$ & 1.52 & 0.155 & \\
\hline \multicolumn{8}{|l|}{ Household income per capita } \\
\hline$\leq 2$ minimun wage & 57.17 & $55.77 ; 58.58$ & 1 & _- & 1 & - & 0.777 \\
\hline 3-6 minimum wage & 56.47 & $54.11 ; 58.83$ & -0.48 & 0.765 & -0.75 & 0.648 & \\
\hline$\geq 6$ minimum wage & 61.21 & $57.48 ; 64.95$ & 1.97 & 0.418 & 1.20 & 0.615 & \\
\hline \multicolumn{8}{|l|}{ Nutrition Status } \\
\hline Not overweight & 56.68 & $54.91 ; 58.46$ & 1 & _ & 1 & _- & 0.986 \\
\hline Overweight & 57.89 & $56.29 ; 59.49$ & 0.6 & 0.562 & -0.02 & 0.986 & \\
\hline \multicolumn{8}{|l|}{ Age } \\
\hline Adolescent & 55.17 & $52.82 ; 57.52$ & 1 & - & 1 & _ & 0.060 \\
\hline Adult & 58.76 & $57.22 ; 60.29$ & 3.27 & $0.013^{*}$ & 3.15 & $0.019 *$ & \\
\hline Elderly & 57.58 & $55.82 ; 59.34$ & 2.44 & 0.07 & 2.25 & 0.103 & \\
\hline
\end{tabular}

${ }^{\text {a }}$ Model adjusted by all variables

${ }^{\mathrm{b}}$ chi-square test

${ }^{\mathrm{c}}$ Wald test

$* \mathrm{p}<0.05$ 
Table 2 shows the mean score of B-HEIR, all variables described by bivariate analysis participated in the multiple model, which was considered appropriate after residue analysis. There was an association between the B-HEIR and lunch consumed away from home.

\section{Discussion}

The present study evaluated the quality of meals consumed away from home and its association with the overall dietary quality.

In Brazil, during the period from 2002 to 2009, the energy contribution of crackers, meats in general, margarine, soft drinks, cheese and other dairy products, sausages, prepared meals and alcoholic beverages remained on the rise, reaching percentage increases ranging from $9 \%$ to $40 \%$ (Levy et al, 2005; Levy et al 2012). The low fruit consumption was also observed in the quality of the meals eaten at home and away from home, with mean scores of the component lower than four points. The same occurs with the high consumption of saturated fat, which appears at breakfast with scores lower than nine points.

The Meal Quality Index score of the lunch, consumed away from home, was lesser than that consumed at home, with the highest concentrations of total and saturated fat. Kearney et al (2001) show that meals eaten away from home contained a lower proportion of protein than the diet as a whole, and more sugars and less iron and vitamins. Other authors also reported that foods consumed away from home are higher in fat, energy-density and lower in fiber, however the average score of the at home MQI in this study, regarding the three meals, was also low, down 50 points (Guthrie et al, 2002; Kant \& Barry, 2004; Lin et al, 1999). This study does not distinguish meals at workplaces and schools consumed in self-service and fast-food areas. Bandoni \& Jaime (2008) and Gorgulho et al. (2011) observed that meals served by the cafeteria of the 
companies, located in the metropolitan region of São Paulo city, had an average score higher than found in this study, both for meals away from home and at home. Although the breakfast consumed away from home had a greater variability of food groups, there was no difference in the final score (MQI) when compared with breakfast consumed at home. For dinner, no difference in relation of the meal consumption quality was observed.

The Meal quality Index developed by Bandoni \& Jaime (2008) was used to evaluate the quality of meals consumed at home and away from home, assessing the overall meal nutritional quality. This index was based on the Revised Dietary Quality Index (Haines et al, 1999), Healthy Eating Index (Kennedy et al, 1995) and Healthy Eating Index adapted for the Brazilian population (Fisberg et al, 2004). This instrument was shown to be valid for evaluation of meals, since the scores correlate positively with the availability of nutrients that are considered to protect against chronic noncommunicable diseases, and inversely with the availability of nutrients that are associated with increased risk (Gorgulho et al, 2011).

The linear regression model shows that have lunch away from home leads to an average reduction of six points in the B-HEIR, independent of gender, income per capita, nutritional status and age.

There was no statistically significant association between the B-HEIR and per capita income and nutritional status. However it seems that women choose healthier foods to consume when compared to men. The same was observed by Blanck et al (2009) that showed that the likelihood of always or often choosing healthy foods was higher among women compared with men. The survey found that the factor that most influenced the choice of the food for lunch was convenience $(34.3 \%)$, followed by taste (27.8\%), cost (20.8\%), and health (17.1\%) (Blanck et al, 2009).

There is no agreement in literature about the definition of eating away from home. Although the definition used in this study has been used previously (Kearney et 
al, 2001; Orfanos et al, 2007), some authors define eating away from home as foods prepared outside the home irrespective of place of consumption (Burns et al, 2002; Lin et al, 1999). USDA and Australian data suggest that the energy content of commercially prepared meals may be higher than that of meals prepared at home (Guthrie et al, 2002; Lin et al, 1999).

A limitation of BHEI-R and MQI in this study is that both indexes rely on dietary data for a single 24-hour period. Therefore, usual intakes cannot be estimated. However, mean usual intake among a population of individuals can be obtained if individual questionnaires are obtained for every day of the week and throughout all four seasons of the year as was the case for ISA Capital-2008 (Guenther et al, 2007).

\section{Conclusion}

Considering that diet is a modifiable risk factor for obesity and other chronic diseases, therefore it is necessary to increase the intake of determined nutrients, such as fiber and calcium, and reduce the intake of fat, satured fat and sodium, independent of the meal consumption location, both at home and away from home. Our results confirm previous results that lunch consumed away from home had the worst quality compared with lunch consumed at home, being higher in total and saturated fat. However, even with a better score, the meals consumed at home also need improvement. Efforts to stimulated and support healthier choices, independent of the local that the meal is consumed should be undertaken.

\section{Acknowledgment}

We wish to thank Maria Cecília Goi Porto Alves for the sampling design of the study.

\section{References}

Associação Brasileira das Empresas de Refeições Coletivas - ABERC, 2012. Mercado 
real de refeições. [Acessed 24 July 2012]. Available at $<$ URL http://www.aberc.com.br/base.asp?id=3>.

Abreu ES, Garbelotti ML, Torres EAFS, 2005. Dietary fiber consumption and composition foods in "by-the-kilo" restaurants. Nutr Food Science; 35(6):386-392.

Bandoni DH, Jaime PC,2008. A qualidade das refeições de empresas cadastradas no Programa de Alimentação do Trabalhador na cidade de São Paulo. Rev. Nutr; 21(2):177-184.

Befort C, Kaur H, Nollen N, Sullivan DK, Nazir N, Choi WS, Hornberger L, Ahluwalia JS, 2006. Fruit, vegetable, and fat intake among non-Hispanic black and non-Hispanic white adolescents: associations with home availability and food consumption settings. J Am Diet Assoc;106:367-373.

Bes-Rastrollo M, Basterra-Gortari FJ, Sa'nchez-Villegas A, Marti A, Martinez JA, Martinez-Gonzales MA, 2010. A prospective study of eating away-from-home meals and weight gain in a Mediterranean population: the SUN (Seguimiento Universidad de Navarra) cohort. Public Health Nutr;13(9):1356-1363.

Blanck HM, Yaroch AL, Atienza AA, Yi SL, Zhang J, mâsse LC, 2009. Factors influencing lunchtime food choices among working Americans. Health Eduction \& Behavior; 36(2):289-301.

Burns C, Jackson M, Gibbons C, Stoney RM, 2002. Foods prepared outside the home: association with selected nutrients and body mass index in adult Australians. Pub Health Nutr;5:441-48.

Fisberg RM, Slater B, Barros RR, Lima FD, César CLG, Carandina L et al, 2004. Índice de Qualidade da Dieta: avaliação da adaptação e aplicabilidade. Rev Nutr; 17(3):301308. 
Gorgulho BM, Previdelli AN, Marchioni DML, 2011. Qualidade das refeições servidas em uma Unidade de Alimentação e Nutrição de uma indústria da região metropolitana de São Paulo. Rev Nutricão; 24(3):463-72.

Guenther PM, Reedy J, Krebs-Smith SM, Reeve BB, Basiotis PP, 2007. Development and evaluation of the Healthy Eating Index-2005: technical report. Alexandria: Center for Nutrition Policy and Promotion, U.S. Department of Agriculture. Available from: http://www.cnpp.usda.gov/HealthyEatingIndex.htm.

Guthrie JF, Lin B, Frazao E, 2002. Role of food prepared away from home in the american diet, 1977-78 versus 1994-96: changes and consequences. J Nutr Educ Behav.;34(3):140-50.

Haines PS, Siega-Riz M, Popkin BM, 1999. The diet quality index revised: a meansurement instrument for populations. J Am Diet Assoc; 99(6):697- 704.

Kant AK, Graubard BI,2004. Eating out in America, 1987- 2000: trends and nutritional correlates. Prev Med; 38:243-9. 19.

Kearney JM, Hulshof KFAM, Gibney MJ, 2001. Eating patterns temporal distribution, converging and diverging foods, meals eaten inside and outside of the home implications for developing FBDG. Public Health Nutr; 4:693-8.

Kennedy ET, Ohls J, Carlson S, Fleming K, 1995. The Healthy Eating Index: design and applications. J Am Diet Assoc;95:1103-8.

Levy-Costa RB, Sichieri R, Pontes N dos S, Monteiro CA, 2005. Disponibilidade domiciliar de alimentos no Brasil: distribuição e evolução (1974-2003). Rev Saúde Pública;39(4):530-540.

Levy-Costa RB, Claro RM, Mondini L, Sichieri R, Monteiro CA, 2012. Distribuição regional e socioeconômica da disponibilidade domiciliar de alimentos no Brasil em 
2008-2009. Rev Saúde Pública;46(1):6-15.

Lin B, Frazão E, Guthrie J, 1999. Away-from-home foods increasingly important to quality of American diet. Washington DC: Food and Rural Economics Division, Economic Research Service. (U.S. Department of Agriculture Information Bulletin, 749).

MS, Ministério da Saúde, 2006. Guia alimentar para a população brasileira: promovendo a alimentação saudável. Brasília, DF.

Moshfegh AJ, Rhodes DG, Baer DJ, Murayi T, Clemens JC, Rumpler WV, Paul DR, Sebastian RS, Kuczynski KJ, Ingwersen LA, Staples RC, Cleveland LE, 2008. The US Department of Agriculture Automated Multiple-Pass Method reduces bias i $\mathrm{n}$ the collection of energy intakes. Am J Clin Nutr;88:324-332.

Nutrition Coordinating Center: Division of Epidemiology Nutrition Data System (NDS), 1998. Nutrition Data System for Research (NDS-R), ed. Minnesota: University of Minnesota.

Orfanos P, Naska A, Trichopoulos D, et al, 2007. Eating out of home and its correlates in 10 European countries. The European Prospective Investigation into Cancer and Nutrition (EPIC) study. Public Health Nutr;10:1515-1525.

Popkin BM, 2001. The nutrition transition and obesity in the developing world. $\mathbf{J}$ Nutr;131:871S-873S.

Popkin BM, Gordon-Larsen P, 2004. The nutrition transition: worldwide obesity dynamics and their determinants. Int J Obesity 28 (Suppl. 3):S2-S9.

Previdelli AN, Caesar S, Pires MM, Vivolo SRF, Firberg RM, Marchioni DML, 2011. Índice de Qualidade da Dieta Revisado (IQD-R): desenvolvimento para aplicação na 
população brasileira. Cadernos de Saúde Pública; 45(4): 794-798.

Satia JA, Galanko JA, Siega-Riz AM, 2004. Eating at fast-food restaurants is associated with dietary intake, demographic, psychosocial and behavioural factors among African Americans in North Carolina. Public Health Nutr;7:1089-1096.

Schmidt M, Affenito SG, Striegel-Moore R, Khoury PR, Barton B, Crawford P, Kronsberg S, Schreiber G, Obarzanek E, Daniels S, 2005. Fast-food intake and diet quality in black and white girls: the National Heart, Lung, and Blood Institute Growth and Health Study. Arch Pediatr Adolesc Med;159:626-631.

Schroder H, Montserrat F, Covas MI, 2007. Association of fast food consumption with energy intake, diet quality, body mass index and the risk of obesity in a representative Mediterranean population. British Journal of Nutrition;98:1274-1280.

StataCorp, 2007. Stata Statistical Software: Release 10. College Station, TX: StataCorp LP.

WHO, World Health Organization; 2003. Diet, nutrition and the prevention of chronic diseases. Report of a joint WHO/FAO Expert Consultation. Geneva. (WHO-Technical Report Series, $\left.n^{\circ} 765\right)$.

Ziegler P, Briefel R, Ponza M, Novak T, Hendricks K, 2006. Nutrient intakes and food patterns of toddlers' lunches and snacks: influences of location. J Am Dietetic Assoc; 106(1S):124-34

\section{CONSIDERAÇÕES FINAIS}

Esta dissertação teve como objetivo principal investigar a qualidade nutricional da alimentação fora do lar e sua relação com características sociais, demográficas e de estilo de vida dos indivíduos que relataram fazer refeições neste contexto. 
A partir do relatado no manuscrito 1, conclui-se que apesar de ter sido identificada relação entre o hábito de comer fora do lar e excesso de peso, as refeições consumidas fora do lar no município de São Paulo foram compostas tanto de alimentos integrantes de uma dieta não saudável, refrigerantes, salgados, sanduíches e pizzas, como também de alimentos marcadores de uma dieta saudável, a exemplo do arroz e feijão.

No manuscrito 2 relata-se a observação de que almoçar fora de casa associou-se à qualidade da dieta, independente do sexo, renda familiar per capita e estado nutricional. Ressaltando que, apesar do almoço realizado fora de casa apresentar maior teor de gorduras total e saturada, a qualidade nutricional das refeições consumidas dentro de casa também está aquém do ideal.

Por fim, devido à escassez de dados relativos ao consumo alimentar fora do lar, em especial das características das refeições, e a complexidade da escolha alimentar, faz-se necessário um maior aprofundamento no estudo dos determinantes destas escolhas, possibilitando, assim, um melhor entendimento das suas repercussões na saúde e possíveis políticas de educação e prevenção, incluindo pesquisas acerca das influências dos fatores ambientais nas escolhas alimentares. 


\section{REFERÊNCIAS}

Associação Brasileira das Empresas de Refeições Coletivas - ABERC. Mercado real de refeições. São Paulo, 2011 [Acesso em 10 de outubro de 2011]. Disponível em < URL http://www.aberc.com.br/base. $\cdot$ asp?id=3 $>$.

Abreu ES, Garbelotti ML, Torres EAFS. Dietary fiber consumption and composition foods in "by-the-kilo" restaurants. Nutr Food Science. 2005; 35(6): 386-392.

Bandoni DH, Jaime PC. A qualidade das refeições de empresas cadastradas no Programa de Alimentação do Trabalhador na cidade de São Paulo. Rev. Nutr., 2008; 21(2):177-184.

Barr SI, Murphy SP, Poos MI. Interpreting and using the Dietary Referente Intakes in dietary assessment of individuals and groups. J Am Diet Assoc. 2002; 102(6):780-788.

Beaton GH, Milner J, Corey P, McGuire V, Cousins M, Stewart E, Ramos M, Hewitt D, Granbsch PV, Kassim N, Little JA. Sources of variance in 24; hour dietary recall data: implications for nutrition study design and interpretation. Am J Clin Nutr. 1979; $32: 2546-59$.

Bezerra NI, Sichieri R. Eating out of home and obesity: a Brazilian nationwide survey. Public Health Nutrition 2009; 12(11):2037-43.

Bezerra NI, Sichieri R. Characteristics and spending on out-of-home eating in Brazil. Rev Saúde Pública 2010;44(2):1-9.

Block G, Dresser CM, Hartman AM, Caroll MD. Nutrient sources in the American diet: quantitative data from the NHANES II survey. I. Vitamins and minerals. Am J Epidemiol. 1985; 122(1):13-26.

Brasil. Ministério da Saúde. Secretaria de Atenção à Saúde. Departamento de Atenção Básica. Política Nacional de Alimentação e Nutrição. $2^{\mathrm{a}}$ ed. rev. Brasília: Ministério da Saúde; 2008.

Burns C, Jackson M, Gibbons C, Stoney RM. Foods prepared outside the home: 
association with selected nutrients and body mass index in adult Australians. Public Health Nutrition 2002; 5(3):441-8.

Carriquiry AL. Assessing the prevalence of nutrient inadequacy. Public Health Nutr. 1999; 2:23-33.

Carriquiry AL. Estimation of usual intake distributions of nutrients and foods. J Nutr. 2003; 133:601S-608S.

Cervato AM, Vieira VL. Índices dietéticos na avaliação da qualidade global da dieta. Rev Nutr 2003; 16: 347-355.

Cesar CLG, Carandina L, Alves MCGP et al. Saúde e condições de vida em São Paulo Inquérito multicêntrico de saúde no Estado de São Paulo. Faculdade de Saúde Pública, USP. 2005.

Coutinho JG, Cardoso AJC, Toral N, Silva ACF, Ubarana JA, Aquino KKNC, Nilson EAF, Fagundes A, Vasconcellos AB. A organização da Vigilância Alimentar e Nutricional no Sistema Único de Saúde: histórico e desafios atuais. Rev Bras Epidemiol. 2009; 12(4): 688-99.

Dodd KW, Guenther PM, Freedman LS, Subar AF, Kipnis V, Midthune D et al. Statistical methods for estimating usual intake of nutrients and foods: a review of the theory. J Am Diet Assoc. 2006;106:1640-1650.

Dwyer J, Picciano MF, Raiten DJ. Future directions for the integrated CSFIINHANES: What We Eat in America - NHANES. J Nutr. 2003; 133:576S-81S.

Federação das indústrias de São Paulo - FIESP, Instituto Brasileiro de Opnião Pública e Estatística - IBOPE. Brasil Trendes Foods 2020. São Paulo, 2011. [Acesso em 25 de $\begin{array}{llll}\text { outubro } & \text { de } & \text { 2011]. } & \text { Disponível em }\end{array}$ <http://www.brasilfoodtrends.com.br/Brasil_Food_Trends/files/publication.pdf>.

Fisberg RM, Slater B, Barros RR, Lima FD, César CLG, Carandina L et al. Índice de Qualidade da Dieta: avaliação da adaptação e aplicabilidade. Rev Nutr. 2004; 
17(3):301-308.

Fisberg RM, Slater B, Marchioni DML, Martini LA. Inqquéritos alimentares: métodos e bases científicos. São Paulo: Manole; 2005. 334p.

Gorgulho BM, Previdelli AN, Marchioni DML. Qualidade das refeições servidas em uma Unidade de Alimentação e Nutrição de uma indústria da região metropolitana de São Paulo. Rev Nutricão. 2011; 24(3):463-72.

Gravina-Taddei Cf, Batlouni M, Sarteschi C, et al. Hyperhomocysteinemia as a risk factor for coronary atherosclerotic diseases in the elderly. Arq Bras Cardiol. 2005; 85 (3): 166-73.

Haines PS, Siega-Riz M, Popkin BM. The diet quality index revised: a meansurement instrument for populations. J Am Diet Assoc. 1999; 99(6):697- 704.

Harttig U, Haubrock J, Knüppel S, Boeing H. The MSM program: web-based statistics package for estimating usual dietary intake using the Multiple Source Method on behalf of the EFCOVAL. Consortium European Journal of Clinical Nutrition. 2011; 65, S87S91.

Hoffman K, Boing H, Dufour A, Volatier JL, Telman J, Virtanem M, Becker W, Henauw S. Estimating the distribution of usual dietary intake by short;term measurements. Eur J Clin Nutr 2002; 56(Suppl.2):53S-62S.

Inagami S, Cohen DA, Finch BK, Asch SM. You are where stop: grocery store locations, weight and neightbohoods. Am J Prev Med 2006; 31:10-17.

Instituto Brasileiro de Geografia e Estatística - IBGE. Pesquisa de Orçamentos Familiares: Análise do consumo alimentar pessoal no Brasil. Rio de Janeiro; 2011. [acesso em 18 de outubro 2011]. Disponível em <URL: http://www.ibge.gov.br/home/presidencia/noticias/noticia_visualiza.php?id_noticia=164 8\&id_pagina $=1>$.

Institute of Medicine - IOM. National Academy Press. Dietary Reference Intakes: 
application in Dietary Assessment. Washington DC: National Academy Press; 2000. $306 \mathrm{p}$.

Institute of Medicine - IOM. Food and Nutrition Board Dietary Reference Intakes for Water, Potassium, Sodium, Chloride, and Sulfate. Washington, DC. The National Academic Press; 2004.

Kant AK, Schatzkin A, Ziegler RG, Nestle M. Dietary diversity in the US population, NHAMES, 1976-198. J. Am.Diet. Assoc. 1991; 91(12): 1526-1531.

Kant AK. Indexes of overall diet quality: a review. J. Am. Diet Assoc. 1996; 96: 785791.

Kant AK, Graubard BI. Eating out in America, 1987- 2000: trends and nutritional correlates. Prev Med 2004; 38:243-9. 19.

Kearney JM, Hulshof KFAM, Gibney MJ. Eating patterns temporal distribution, converging and diverging foods, meals eaten inside and outside of the home implications for developing FBDG. Public Health Nutr 2001; 4:693-8.

Kennedy ET, Ohls J, Carlson S, Fleming K. The Healthy Eating Index: design and applications. J Am Diet Assoc 1995;95:1103-8.

Levy-Costa RB, sichieri R, Pontes NS, Monteiro CA. Disponibilidade domiciliar de alimentos no Brasil: distribuição e evolução (1974-2003). Rev Saúde Pública 2005; 39(4): 530-40.

Lin B, Frazão E, Guthrie J. Away-from-home foods increasingly important to quality of American diet. Washington DC: Food and Rural Economics Division, Economic Research Service; 1999. (U.S. Department of Agriculture Information Bulletin, 749).

Lustosa TQ de O. Para que servem os dados sobre consumo alimentar? In: Consumo alimentar: as grandes bases de informação: simpósio. São Paulo: Instituto Danone; 2000. p.53-61.

Ma Y, Bertone ER, Stanek EJ, Reed GW, Hebert JR, Cohen NL, et al. Association 
between eating patterns and obesity in a free-living US adult population. Am $\mathbf{J}$ Epidemiol 2003; 158:85-92.

Maddock J. The relationship between obesity and the prevalence of fast foods restaurants: state-level analysis. Am J Health Promt 2004; 19:137-143.

Malta DC, Cezário AC, Moura L, Morais Neto OL, Silva Júnior JB. A construção da vigilância e prevenção das doenças crônicas não transmissíveis no contexto do Sistema Único de Saúde. Epidemiologia e Serviços de Saúde. 2006; 15(3):47-65.

Ministério da Saúde. Guia alimentar para a população brasileira: promovendo a alimentação saudável. Brasília, DF; 2006.

Monteiro C.A., Mondini L, Souza ALM, Popkin BM. The nutritional transition in Brasil. Eur J Clin Nutr, 1995, 45: 105-113.

Monteiro CA, Mondini L, Souza ALM, Popkin BM. Da desnutrição para a obesidade: a transição nutricional no Brasil. In: Monteiro, CA, organizador. Velhos e novos males da saúde no Brasil. 2.ed. São Paulo: Hucitec; 2000. p.247-255.

Monteiro CA, Mondini L, Costa RBL. Mudanças na composição e adequação nutricional da dieta familiar nas áreas metropolitanas do Brasil (1988;1996). Rev Saúde Pública. 2000; 34(3):251-8.

Morland K, Diez Roux AV, Wing S. Supermarkers, other food stores, and obesity: the Atherosclerosis risk in communities study. Am J Prev Med 2006,30(4):333-39.

Nielsen S, Popkin B. Changes in beverage intake between 1977 and 2001. Am J Prev Med 2004; 27:205-10.

Orfanos P, Naska A, Trichopoulus D, et al. Eating out of home and its correlates in 10 European countries. The European Prospective Investigation into Cancer and Nutrition study. Public Health Nutrition 2010; 10(12):1515-25.

Paeratakul S, Popkin BM, Kohlmeier L, Hertz;Picciotto I, Guo X, Edwards LJ. Measument error in dietary data: implications for the epidemiologic study of the 
diet;disease relationship. Eur J Clin Nutr 1998; 52:722-727.

Patterson RE, Haines PS, Popkin BM. Diet Quality Index: capturing a multidimensional behavior. J Am Diet Assoc 1994; 94:57-64.

Previdelli AN, Caesar S, Pires MM, Vivolo SRF, Firberg RM, Marchioni DML. Índice de Qualidade da Dieta Revisado (IQD-R): desenvolvimento para aplicação na população brasileira. Cadernos de Saúde Pública. In press.

Rafferty AP, Anderson JV,McGEE HB, Miller CE. A healthy diet indicator : qualifying compliance with the dietary guidelines using the BRFSS. Prev Med 2002; 35: 9-15.

Sociedade Brasileira de Cardiologia. IV Diretriz Brasileira sobre dislipidemias e prevenção da aterosclerose Departamento de Aterosclerose da Sociedade Brasileira de Cardiologia. Arq Bras Cardiol. 2007; 88: 2-19.

Stum R, Datr A. Body mass index in elementary school children, metropolitan area food prices and food outlet density. Public Health 2005; 119(12):1059-68.

Tarasuk V, Beaton G. Statistical estimation of dietary parameters: implications of patterns in within;subject variation - a case study of sampling strategies. Am J Clin Nutr. 1992; 55:22-7.

Thompson FE, Byers T. Dietary assessment resource manual. J Nutr. 1994;124 (Suppl): 2245S-2317S.

Viacava F. Informações em saúde: a importância dos inquéritos populacionais. Ciências \& Saúde Coletiva, 2002; 7(4): 607-21.

Willett W. Nutrition epidemiology. 2 ed. Nova York: Oxford University Press; 1998.

World Cancer Research Fund, American Institute for Cancer Research. Expert report, food, nutrition, physical activity and the prevention of cancer: a global perspective. http://www.dietandcancerreport.org/. Accessed November 26, 2007.

World Health Organization - WHO. The world health report 2002: reducing risks, promoting healthy life. Geneva: WHO, 2002. 
Woteki CE. Integrated NHANES: Uses in National Policy. J Nutr. 2003; 133:582S$584 \mathrm{~S}$.

Ziegler P, Briefel R, Ponza M, Novak T, Hendricks K. Nutrient intakes and food patterns of toddlers' lunches and snacks: influences of location. J Am Dietetic Assoc 2006; 106(1S): 124-34. 
ANEXOS 


\section{Anexo 1 - Recordatório de 24 horas (R24h)}

Nome

Data de vasc:

$\mathrm{N}^{2}$ do questionário

Data da Bntrevista-
Sexo

masculino

fenimino

Entrevistador:

Dia da Sensan do Recordatório

Anote bebidas e aïmentos (ingredientes de preparações) consumidos no dia anterior e os horários. Anote o nome da refeiçä. Näo esqueça das marcas comerciais, medidas caseiras, utensírios (túpo de colher, copo, prato, etc.).

\begin{tabular}{|c|c|c|c|c|}
\hline Horário & $\begin{array}{l}\text { Nome da } \\
\text { Refeição }\end{array}$ & $\begin{array}{l}\text { Alimentos, bebidas } \\
\text { e/ou preparaçôes }\end{array}$ & $\begin{array}{c}\text { Tipo / Forma de } \\
\text { Preparo }\end{array}$ & Quantidades \\
\hline & & & & \\
\hline & & & & \\
\hline & & & & \\
\hline & & & & \\
\hline & & & & \\
\hline & & & & \\
\hline & & & & \\
\hline & & & & \\
\hline & & & & \\
\hline & & & & \\
\hline & & & & \\
\hline & & & & \\
\hline & & & & \\
\hline & & & & \\
\hline & & & & \\
\hline & & & & \\
\hline & & & & \\
\hline & & & & \\
\hline & & & & \\
\hline & & & & \\
\hline & & & & \\
\hline & & & & \\
\hline & & & & \\
\hline & & & & \\
\hline
\end{tabular}




\begin{tabular}{|c|c|c|c|c|}
\hline Horário & $\begin{array}{l}\text { Nome da } \\
\text { Refeição }\end{array}$ & $\begin{array}{l}\text { Alimentos, bebidas } \\
\text { e/ou preparaçôes }\end{array}$ & $\begin{array}{c}\text { Tipo / Forma de } \\
\text { Preparo }\end{array}$ & Quantidades \\
\hline & & & & \\
\hline & & & & \\
\hline & & & & \\
\hline & & & & \\
\hline & & & & \\
\hline & & & & \\
\hline & & & & \\
\hline & & & & \\
\hline & & & & \\
\hline & & & & \\
\hline & & & & \\
\hline & & & & \\
\hline & & & & \\
\hline & & & & \\
\hline & & & & \\
\hline & & & & \\
\hline & & & & \\
\hline
\end{tabular}

O(A) ENTREVISTADO(A) CONSUMTU:

\begin{tabular}{|c|c|c|c|}
\hline REFRIGERANTE & () SIM $_{\mathrm{NAO}} \longrightarrow$ & () Light Diet () Nomal & \\
\hline LEITE & () SIM $_{\mathrm{NAO}} \rightleftarrows$ & () Integral () Desantado & () Senvidesnat. \\
\hline SALADA & () ${ }_{\mathrm{NAMO}} \longrightarrow$ & Descrever o tempero utilizado. & \\
\hline BEBDAS & () $)_{N A M O} \rightleftharpoons$ & Verificar se adicionou algo. & \\
\hline
\end{tabular}

Observaçôes 
Anexo 2 - Roteiro para aplicação do R24h pelo Automated Multiple Pass Methods (AMPM) no Nutrition Data System for Research (NDSR)

Descrição de atividades para a coleta de dados

Roteiro para aplicação do R24h pelo método Multiple-Pass do NDS-R

a) Preenchimento dos dados de identificação

Antes de ligar para o indivíduo, consulte o programa de cadastro na Internet (colocar domínio) e preencha os seguintes dados na tela Header do NDS:

- Identificação do Indivíduo (ID ou numquest) no campo "Participant ID";

- Nome completo do entrevistado no campo "Participant Name"; - \&4" digitar com letras maiúsculas e sem acentuação, cedilha ou til.

- Data de nascimento (MM/DD/AAAA) no campo "Data of Intake";

- Sexo no campo "Gender"

- Nome do entrevistador no campo "Interviewer ID"

b) Iniciando a coleta do R24h - listagem rápida dos alimentos e bebidas (Quick-List)

"Meu nome é sou nutricionista da Faculdade de Saúde Pública da USP e gostaria de obter informações sobre todos os alimentos e bebidas consumidos pelo sr(sra) no dia de ontem. 
Primeiramente, o $\operatorname{sr}(\mathrm{sra})$ me dirá quais os alimentos e bebidas e depois eu perguntarei ao(à) sr(sra) sobre o modo de preparo e as quantidades em medidas caseiras. $\mathrm{O}(\mathrm{A})$ sr(sra) tem alguma dúvida?

Em caso de resposta negativa, prosseguir com o roteiro:

"Assim, no dia de ontem, quais foram os alimentos e bebidas que o(a) $\operatorname{sr}(\mathrm{a})$ consumiu desde a hora que levantou até a hora que foi dormir?" - sil iniciar 0 preenchimento do Quick-List.

Ao final do relato, perguntar:

"O(A) $\operatorname{sr}(\mathrm{a})$ se recorda de ter consumido algum outro alimento ou bebida?"

- Caso o indivíduo não relate os horários, locais e refeições, perguntar:

"O(A) sr(a) pode me dizer sobre os horários, locais e quais foram as refeições em que consumiu os alimentos?" - all reler os alimentos e registrar os horários e locais.

c) Detalhamento dos alimentos e bebidas

'Observação: quando o indivíduo não souber informar sobre o modo de"; I preparo dos alimentos e/ou medidas caseiras, digitar no campo Notes do I ! alimento a abreviação "NS prep" ou "NS quant", indicando que o indivíduo ! 
I não soube referir a preparação ou a quantidade consumida, respectivamente. I

- Para obter informações quanto ao modo de preparo, perguntar:

"Como foi preparado o(a) ?" \&(1) Para carnes bovinas, suínas ou aves, preencher no campo "Notes" o modo de preparo e o grau de cocção do alimento (seguir abreviações e definições):

Abreviações:

$\begin{array}{ll}- & \text { Cozido = coz } \\ - & \text { Assado = ass } \\ - & \text { Grelhado = gre } \\ - & \text { Microondas = micr } \\ - & \text { Frito = fr } \\ - & \text { Ensopado = ensop }\end{array}$

Definições

هil) Carne bovina

"A carne que o(a) sr(a) consumiu estava ?"

- $\quad$ Mal passada (mp): apresenta sangue ao cortar;

- $\quad$ Ao ponto (ap): apresenta cor rosada ao cortar, sem sangue;

- $\quad$ Bem passada (bp): não apresenta cor rosada ao cortar, sem sangue e por fora apresenta coloração escura; 
- $\quad$ Muito bem passada (mbp): não apresenta cor rosada ao cortar, sem sangue e por fora apresenta coloração bem escura (quase queimada) na maior parte da carne.

\section{0il) Carne suína e Aves:}

- $\quad$ Passada (p): não apresenta sangue ao cortar;

- $\quad$ Bem passada (bp): não apresenta sangue ao cortar, com coloração escura nas bordas;

- $\quad$ Muito bem passada (mbp): não apresenta sangue ao cortar, com coloração escura na maior parte da carne.

* Para obter informações quanto ao tipo do alimento, perguntar:

“Qual era o tipo de(a) (o) ?"

Para obter informações quanto à procedência, perguntar:

“O(A) foi preparado em casa ou foi comprado?"

Para obter informações quanto à característica do alimento, perguntar:

“O(A) era fresco, enlatado ou congelado?" 
c1) Adição de alimentos às bebidas e de temperos às saladas

Para obter informações quanto à adição de açúcar, adoçante ou outro alimento às bebidas, perguntar:

“O(a) sr(a) adicionou algo à(ao) ?"

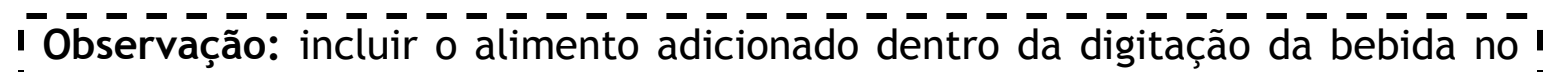
I item Food/Additions.

* Para obter informações quanto à adição de condimentos ou molhos à salada, perguntar:

“O(a) sr(a) acrescentou algum tempero ou molho à salada?" - \&all se a resposta for afirmativa, perguntar:

“Qual(quais) o(s) tempero(s) ou molho(s) utilizados?”

\section{c2) Quantificação dos alimentos e bebidas}

Para obter informações quanto à medida caseira, perguntar:

"Qual o utensílio o(a) sr(a) utilizou o para se servir do(a) ?"

- all válido para todos os alimentos, exceto as bebidas. 
“Qual o utensílio o(a) sr(a) utilizou o para beber o(a) ?" - (\$) válido para as bebidas.

* Para obter informações quanto ao tipo de utensílio, perguntar:

"Qual o tipo de (utensílio em questão) foi utilizado(a)?

Īobservação: Informações referentes à pratos (com exceção de saladas), I tigelas e cumbucas devem ser evitadas. Nestes casos, perguntar:

" “O(A) sr(a) se recorda do utensílio utilizado para se servir deste alimento?”

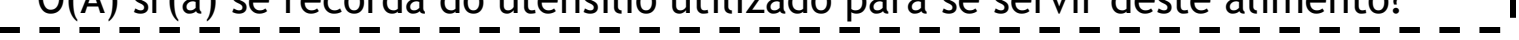

Para obter informações quanto ao tamanho da porção/alimento, perguntar:

"O tamanho do(a) era pequeno, médio ou grande? (alimento em questão/utensílio em questão)

“O(A) (utensílio em questão) estava raso(a), normal ou cheio(a)?

IOb̄érvação: Digitar no campo Quantity o código numérico 9999 e no campo i INotes as medidas caseiras abreviadas, conforme lista abaixo:

Colheres

- $\quad$ Colher de servir = c servir

- $\quad$ Colher de pau = c pau

\section{Conchas}

- Concha pequena = conc peq

- Concha média = conc med

- Concha grande = conc grd 
- $\quad$ Colher de sopa = c sopa

- $\quad$ Colher de chá = c cha

- Colher de café = c cafe Copos

- $\quad$ Colher de sobremesa $=\mathrm{c}$ sob

- Copo tipo americano = cp amer

- Copo tipo requeijão $=\mathrm{cp}$ req

- Copo descartável= cp desc

Xícaras

- $\quad$ Xícara de café $=$ xic cafe

- $\quad$ Xícara de chá = xic cha

Pratos

- Prato raso $=$ prt $r$

- Prato fundo = prt fd

Canecas $=$ can

Os tamanhos das porções pequeno, médio e grande seguirão às seguintes abreviações:

- $\quad$ Pequeno $=$ peq

- $\quad$ Médio $=$ med

- $\quad$ Grande $=$ grd

Todas as informações deverão ser digitadas SEM ACENTOS.

d) Finalizando a coleta do $R 24 \mathrm{~h}$ - preenchimento da tela Trailer

Perguntar:

"A quantidade de alimentos que o(a) sr(a) consumiu ontem foi a quantidade habitual, foi mais que a habitual ou menos que a habitual?" - soll caso o 
indivíduo responda mais ou menos que a habitual digitar no campo Notes as razões mencionadas pelo entrevistado. 


\section{Anexo 3 - Pareceres dos Comitês de Ética em Pesquisa}

\section{Aprovação do ISA - Capital 2008 pelo Comitê de Ética em Pesquisa da Secretaria Municipal da Saúde (CEP/SMS), com parecer número 027/08 - CEP/SMS.}

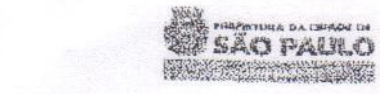

Para

Prof Dr. Moisés Goidbaum

Sria) Pesquisador(a)

$X$ - Jdentificação

* Título do projeto: Inquérito de Saúde de base populacional no Município die Sta pawlo

- Instituição onde se realizará: Municipio de São Pauto

Tipo de projeto: inquérito de base populacional sobre Saúde Domicillar.
- Pesquisador responsável: Prof Dr. Moises Golttbaum

\section{II - Dbjetivos.}

- Oferecer um banco de dados coun todas as informaçöes colnidas que permitam:

2- analisar a desigualđade social (de gênero, cor/raça e classe socia!) de nionbidad

betes) e de uso de serviços de saúde (incluindo práticas preventitivas) emorn adultos.

- Estudar a assoclação entre comportamentos, morbidades e uso de serviços de sauide.

III - Sumário do Projeto:

1. Desenho getral do projeto:

A desiguaidade social de acesso à uso de serviços de saúde e as praticas preventives é diferenciăda

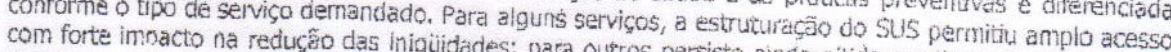
estratos sociais de ma reduço das miquidades: para outros persiste ainda nitido gracliente favorecendo os cas, entretanto, como a vacinaçado de idosos, verifica et al, 2005, Zaitune et al, 2006). Pare algumas prátisocioeconómico cobertos pelo SUS (Francisco verifica-se maior vtilizaçäo pelos segmentos de menor nivel

Ereconhecido que parte substaicial of d et al, 2006).

ferenças no padrăo de comportamentos rítiferenģas sociais em morbidade e mortalidade decorre das dio que enfatiza a necessidade de aprofundamento das investigacós e Wardle, 1999 ; Huismãn et al, 2004), em relaçăo a estes fatores țe risco de doencas crônios investigaçoes e do monitoramento das intervencóes a coexistir, tomando importante identificar ças cronicas. Os connentamentos prejudiciais à saúde tencern de meihores intervençōes.

Considerando o impacte

e a tendência de concentraçăo destes conpontaño saudáveis no perfil astuál é futuro da morbimortalidade torna-se relevante identificar os subgrupos com maior vumentos socialmente mais desfavorecidos, liticas e pregramas de promoção da saúde com maior vulnerabilifade, de forma a nortear poO monitoramento do prado de saúla saude e de conkrole de fatores de risco.

çấo das políticas e dos programas de saúde (Viacuava, 2002), sendo de interaf perra a forryulaçáo e avafiares de governo e da scciedade, em geral, na busca de melhores patamares de sove todos do nives e seto-

2. Adequação da metodologią:

Desenho e populaça de estudo

Os dados serõo obridos em ing a

Säo Paulo. Serräo coletadas informaçöes de pailar de base populacional a ser desenvolvido no municipio de 


\section{Amostra}

Paa a itanzaçao do incuérito será utilizada amostragem em obis estacjios: setores censitarios e domicilios. Os sefores censitários serḱ soreados com probabilidade proporciunal a tarienno (número de domicilios) e, antes do sortelo, serão ordenados segundo indicadores de escolandacle, derivados de informaçöes do censo demogréfico de 2000. Nos setores sorteados, seräo listacos todos os enderəços, com a infornaça sobre a existância de gesterntes no último trimestre de gravidez e menores de ufn ano.

o sortelo será feito de forma a obter um minimo de 400 entre vistas para oada un dos seguintes dominh os de sexo e idade: menores de um ano, crianças de 1 a 11 anos de idade, homens e muhneres de 12 a 17 anos, de 18 a 59 anos e de 60 anos e mais.

O tarnanho minimo de 400 possibilita estimar uma prevalènciá de 0,5 com erro de 0,07 considerando um erto alfa de 0,05 e um efeito de delineamento de 2. Para compensar as possiveis perdas (máxirno de $20 \%$ ), serăo sorteados 500 individuos de cada dominio.

\section{Entrevistas}

O questionário da pesquisa incluirá conjuntos temáticos sobre: condiçöes socioeconönicas do entrevistado, caracteristicas da familia e domicilio, morbidade nos uttimos quinze dias, utilizaçăo de serviģes de saúde, matemo-infantil, doenças crónicas, corn anfase em hipertensäo e diabetes, dericithncias fisicas, práticas preventivas: oâncer de mama, de colo de útero e de próstata e saúde mentat do inquérito is, 2002 (disponivel no site uww fso, usp. brilsa, sp).

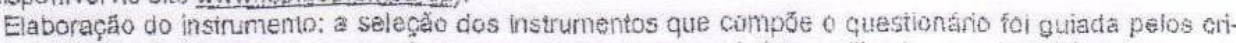
térios de adocåo, sempre que possivel, de instrumentos e conteúdos utlizatdos em inquéritos nacionais como as PNADs, INCA - MS, e instrumentos previamente validados no Brasti, e avestiados quanto à qualidade e potencialidede dos Indicadores e varláveis gerados.

Uma revisăo deverá ser realizada visando a contemplar a necessidade definida pelos gestores locais, contratantes deste inquérito

As entrevistas seräo aplicadas nos domicilios, por entrevistadores treinados, dirotamente à pessoa sorteada.

A pesquisa garantira o anonimato do participante que assinart um termo de consentimento esclarecido antes de respender o questionário. $O$ projeto sera encaminhado ao Comitè de Ética da FivişP e, se necessário, às das demais instituições envolvidas.

\section{IV-Comentários}

1. Estrutura do protocolo: adequada

2. Anállse de riscos e baneficios: A pesquisa aparentemente não oferece riscos e seus resultados poderăo contribuir para o planejarnento das açōes de saúcie.

3. Termo de consentimento e forma de obtê-lo: adequado

4. Financiamento: adequado

5. Cronograma: adequado

\section{V- Parecer do CEP: Projeto Aprovado}

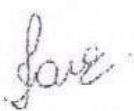




\title{
Aprovação do Estudo Complementar ISA - 2008 pelo Comitê de Ética em Pesquisa da Faculdade de Saúde Pública (COEP/FSP)
}

\author{
COMTTÉ DE ÉTICA EM PESQUISA - COEP/FSP \\ Universidade de São Paulo \\ Faculdade de Saude Pública
}

OF.COEP/27s/og

Sä० Pawl, IG de sebernbro de 2009.

Prezado(a) Pesquisodor(o) c Orichtador(a).

o comitè de tíca em pesqursa da Faculdade de Saude Publica da Universidade de

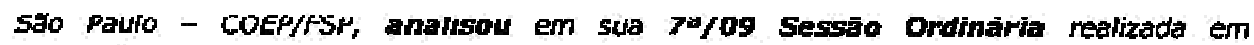
11/09/2009, de acordo com a Resoiuça N." 1 95/y6 do Conselho Nacional de Sadide - CNS

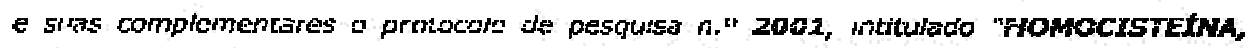
POLTMORFISMOS DO GENE MTHFR, FATORES ULIETICOS E RISCO CARDTOVASCULAR: ESTUDO DE BASE POPULACIONAL - ISA-CAMIIAL", drea tematica GRUPO III, sub resporsobilidade do(a) pesquisador(a) Dine Maria Labo Marchioni, e

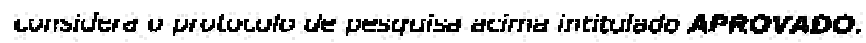

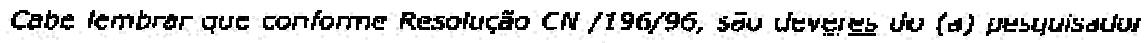

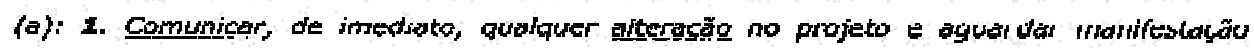

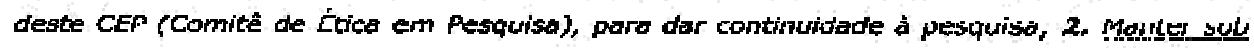
sue guando $\mathrm{c} \mathrm{cm}$ locel sequro pelo prazo de 5 (cinco) anos, os dadus da pesquisa, contendo Fichos individuris c todos os demais documentos repomerdados pelo CEP, no caso eventual auditoria; 3. Commicar, formulmente a este Comite, quendo do encerramento deste

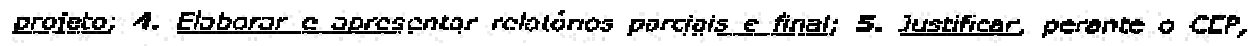

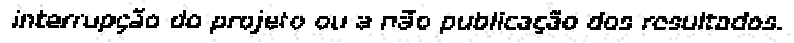

Atenciosamente,

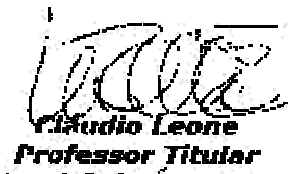

Coordenador do conite de Etica em Pesquisa - COEP

Ihm: Sr.:

Frof. $=$ Dr. Dince Maria Lobo Marchioni

Departamento de Nutricáo

Facufdade de Saúde Pública - USP

Av, Dr, Arnalda, 715 - Assessui ia Acadêrnilud - CFP: 01246-904 - Sấa Paulo - SP

Telefones: (55-11) 3061-7779/7747 e-mail: rnengffs. usp.br site wiww.fsp.usp.br 


\section{Aprovação do Presente Estudo pelo Comitê de Ética em Pesquisa da Faculdade de Saúde Pública (COEP/FSP)}

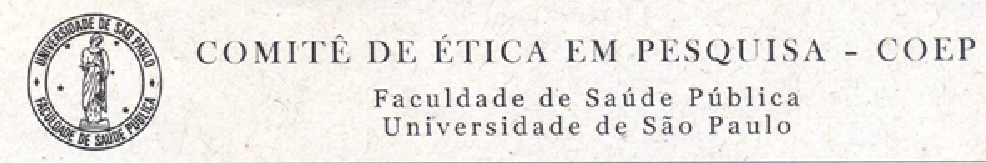

OF.COEP/199/11

20 de junho de 2011.

Prezadas pesquisadora e orientadora,

O Comitê de Ética em Pesquisa da Faculdade de Saúde Pública da Universidade de São Paulo, em sua 5.a/11 Sessão Ordinária, realizada em 17/6/2011, analisou de acordo com a Resoluçăo n. 196/96 do Conselho Nacional de Saúde e suas cómplementares, o protocolo de pesquisa n* 2247, intitulado "ALIMENTAÇÃO FORA DO LAR E SUA RELAÇÃO COM A QUALIDADE DA DIETA DE MORADORES DO MUNICIPIO DE SÃO PAULO: ESTUDO ISACAPITAL", do grupo III, sob responsabilidade da pesquisadora Bartira Mendes Gorgulho e orientação da Professora Dirce Maria Lobo Marchioni, considerando-o APROVADO.

Cabe lembrar que, de acordo com a Res. CNS 196/96, sāo deveres do(a) pesquisador(a) 1) Comunicar de imediato qualquer alteração no projeto e aguardar manifestaçăo deste Comitế de Ética em Pesquisa para dar continuidade à pesquisa; 2) Manter sob sua guarda e em loca seguro, pelo prazo de 5 (cinco) anos, os dados da pesquisa, contendo fichas individuais e todos os demais documentos recomendados pelo COEP, no caso eventual auditoria; 3) Comunicar formalmente a este Comitê quando houver o encerramento da pesquisa; 4) Elaborar e apresentar relatórios parciais e final; 5) Justificar perante 0 COEP interrupção do projeto ou a não publicaçăo dos resultados.

Atenciosamente,

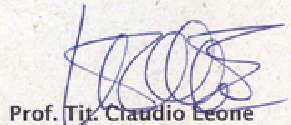

Coordenador do Comitê de Ética em Pesquisa - FSP/USP

IIm a Sr a

Prof a Dr a Dirce Maria Lobo Marchioni

Departamento de Nutrição

Faculdade de Saúde Pública/USP

Av. Dr. Arnaldo, 715 - Cerqueira César - CEP 01246-904-São Paulo - SP Contato: (55 11) 30617779 | coep@fsp.usp.br | www.fsp.usp.br 


\section{Anexo 4 - Termo de Consentimento Livre e Esclarecido}

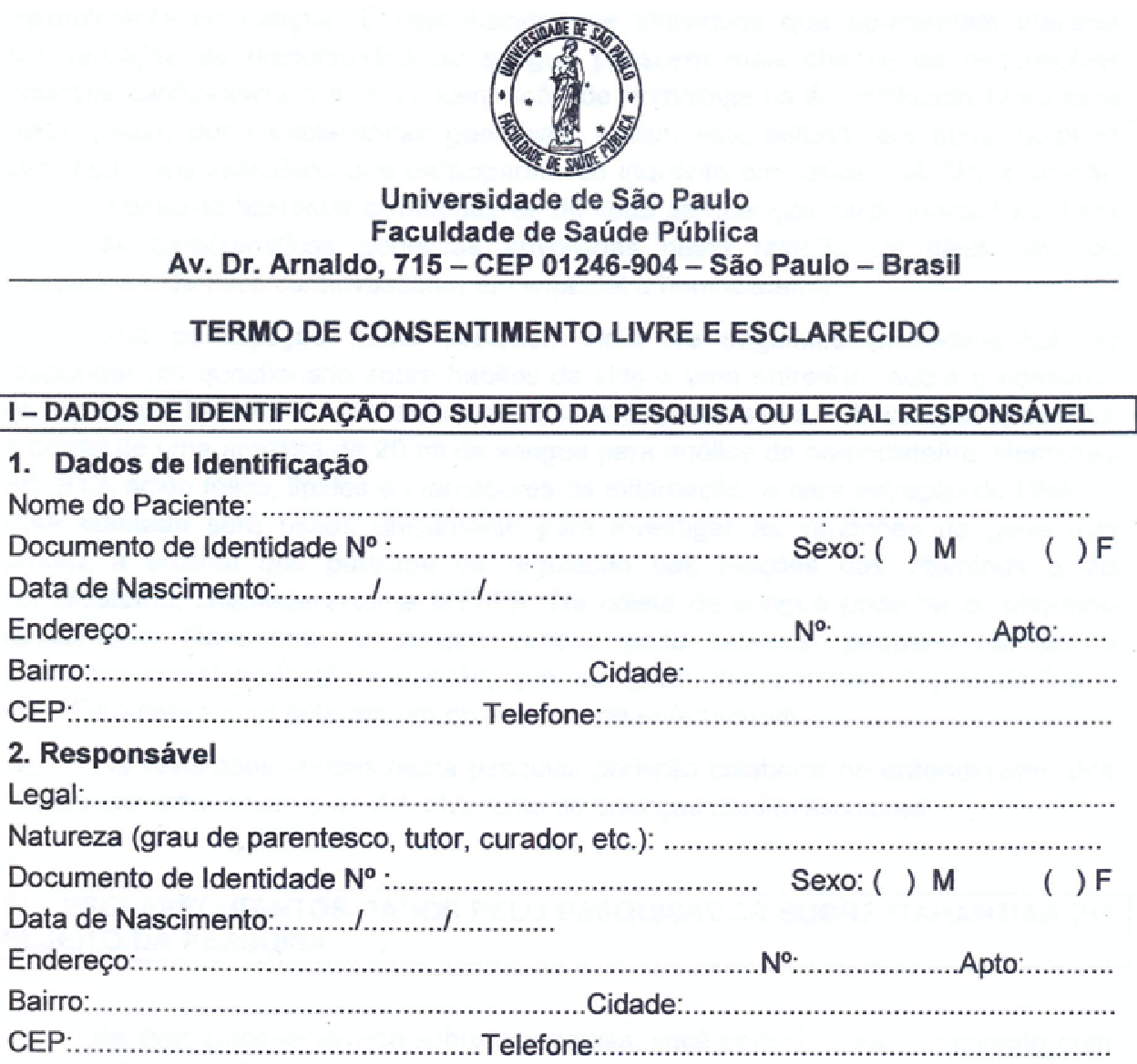

\section{II - DADOS SOBRE A PESQUISA}

1.Título do Protocolo de Pesquisa: Homocisteína, polimorfismos do gene MTHFR, fatores dietéticos e risco cardiovascular: estudo de base populacional ISA-Capital

Pesquisador: Dirce Maria Lobo Marchioni, portadora do documento de Identidade $\mathrm{N}^{\circ}$ 11073227, sexo feminino, exercendo a função de Professor Doutor do Departamento Nutrição da Faculdade de Saúde Pública da USP

\section{Avaliação de Risco da Pesquisa}

Nenhum risco ( ) risco mínimo (x) risco moderado ( ) risco alto ( )

3.Duração da Pesquisa: vinte e quatro meses.

III - REGISTRO DAS EXPLICAÇÕES DO PESQUISADOR AO SUJEITO DA PESQUISA OU SEU REPRESENTANTE LEGAL SOBRE A PESQUISA, CONSIGNANDO:

As doenças cardiovasculares estão entre as doenças que mais afetam os brasileiros e se relacionam com a alimentação. Poucos estudos têm sido realizados no Brasil para investigar os fatores da dieta relacionados com o risco de doenças 
cardiovasculares. Um destes fatores é a homocisteína, um composto encontrado naturalmente no sangue. É reconhecido que individuos que apresentam elevada concentração de homocisteína no sangue possuem mais chance de desenvolver doenças cardiovasculares. A concentração de homocisteína é modificada tanto pela dieta quanto por características genéticas. Assim, este estudo tem como objetivo investigar, nos indivíduos que participaram do inquérito em saúde ISA-SP, a relação entre o consumo alimentar e marcadores de risco de doenças cardiovasculares, bem como as características genéticas envolvidas nesta relação da dieta com os marcadores de risco cardiovascular, em especial a homocisteína.

Sua participação nesta pesquisa inclui os seguintes procedimentos: a) responder um questionário sobre hábitos de vida e uma entrevista sobre o consumo de alimentos; b) permitir fazer as suas medidas de peso, altura e da cintura; c) permitir a coleta de uma amostra de $20 \mathrm{ml}$ de sangue para análise de homocisteína, vitaminas B6, B12, ácido fólico, lipides e marcadores de inflamação, e para extração do DNA. O DNA coletado será usado unicamente para investigar as variações do gene que produz a enzima que participa da regulação das funções das vitaminas e da homocisteína, chamada enzima MTHFR. Na coleta de sangue pode haver pequeno desconforto. Raramente, a punção venosa pode provocar pequeno hematoma (manchas roxas) no local da punção, que, em geral, desaparecem depois de 3 a 5 dias. Esta coleta será feita por um profissional de enfermagem.

Os resultados obtidos nesta pesquisa poderão colaborar no entendimento dos fatores que influenciam o desenvolvimento de doenças cardiovasculares.

IV - ESCLARECIMENTOS DADOS PELO PESQUISADOR SOBRE GARANTIAS DO SUJEITO DA PESQUISA

Se tiver qualquer dúvida sobre a pesquisa, você poderá entrar em contato com a Profa. Dirce Maria Lobo Marchioni pelo telefone: (11) 3061-7856, ou com o Comitê de Ética da FSP/USP (11-3061-7779).

Todas as informações prestadas nesta entrevista são de caráter confidencial e serão utilizadas somente para fins cientificos, sem qualquer identificação pessoal. Esclarecemos que seu consentimento está sendo pedido para este estudo, não sendo extensível a nenhum outro projeto de pesquisa. É garantida e respeitada a privacidade na divulgação dos resultados da pesquisa, e não haverá, de forma alguma, sua identificação.

Qualquer provável benefício para o bem estar da população depende da exatidão de suas respostas. Portanto, se o $\mathrm{Sr}(\mathrm{a})$ não entender alguma das questões, por favor, solicite os esclarecimentos que julgar necessários. Também estaremos a disposição para informá-lo(a) sobre os procedimentos, riscos e benefícios decorrentes da pesquisa, ou qualquer dúvida sobre o estudo.

É garantido o direito de desistir a qualquer momento da participação nesta pesquisa, sem prejuízo algum para você. $\mathrm{O}$ (a) $\mathrm{Sr}(a)$ tem a liberdade de não participar do estudo, ou retirar seu consentimento a qualquer momento. 
V - INFORMAÇÕES DE NOMES, ENDEREÇOS E TELEFONES DOS RESPONSÁVEIS PELO ACOMPANHAMENTO DA PESQUISA PARA CONTATO EM CASO DE INTERCORRÊNCIAS CLÍNICAS E REAÇÕES ADVERSAS.

Você poderá entrar em contato com a Profa. Dirce Maria Lobo Marchioni pelo telefone: (11) 3061-7856, ou email marchioni@usp.br, sobre a pesquisa, ou no endereço: Rua Dr Arnaldo, n 715-Cerqueira César, Sảo Paulo, CEP: 01246-904. Também poderá entrar em contato com o Comitê de Ética em Pesquisa da Faculdade de Saúde Pública, no mesmo endereço, telefone (11) 3061-7779, email: coep@fsp.usp.br.

\section{VI - CONSENTIMENTO PÓS-ESCLARECIDO}

Declaro que, após convenientemente esclarecido pelo pesquisador e ter entendido o que me foi explicado, consinto em participar do presente Protocolo de Pesquisa.

São Paulo de de

Assinatura do sujeito de pesquisa Assinatura do pesquisador ou responsável legal (carimbo ou nome legivel) 
Currículo Lattes 


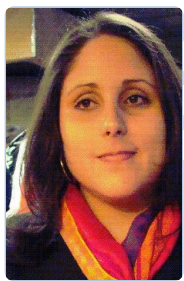

\section{Bartira Mendes Gorgulho}

Endereço para acessar este CV:http://lattes.cnpq.br/5452652233563384

Última atualização do currículo em 29/11/2012

Resumo informado pelo autor

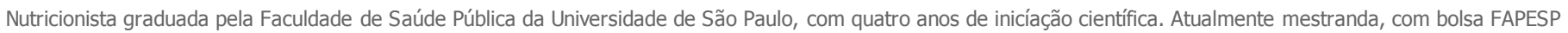

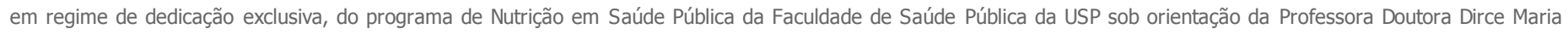
Lobo Marchioni.

(Texto informado pelo autor)

Links para Outras Bases: SciELO - Artigos em texto completo $S$ Sip $L_{0}$

\section{Dados pessoais}

Nome Bartira Mendes Gorgulho

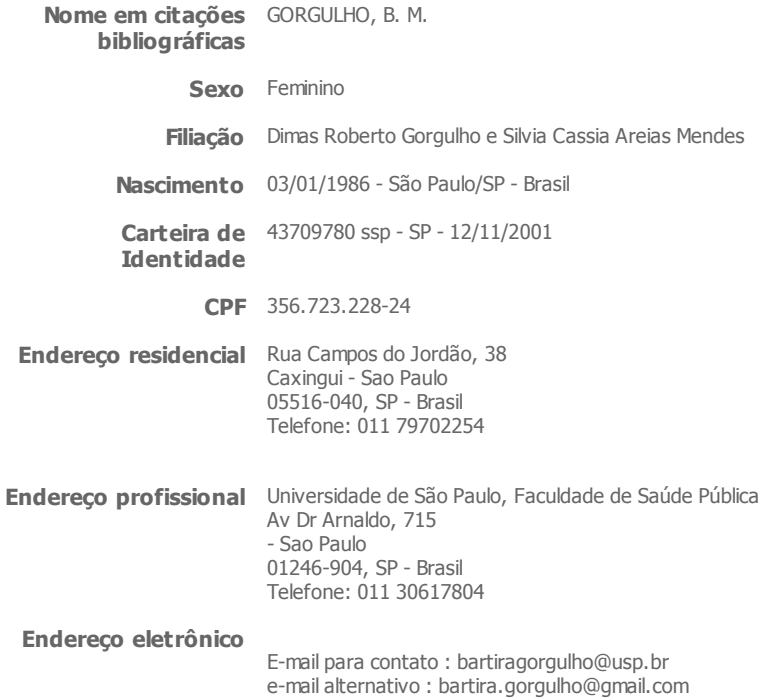

Endereço eletrônico

E-mail para contato : bartiragorgulho@usp.br

e-mail alternativo : bartira.gorgulho@gmail.com

Formação acadêmica/titulação

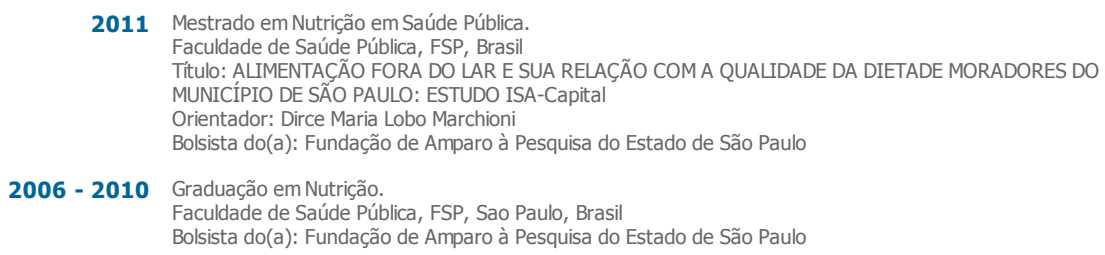

Formação complementar

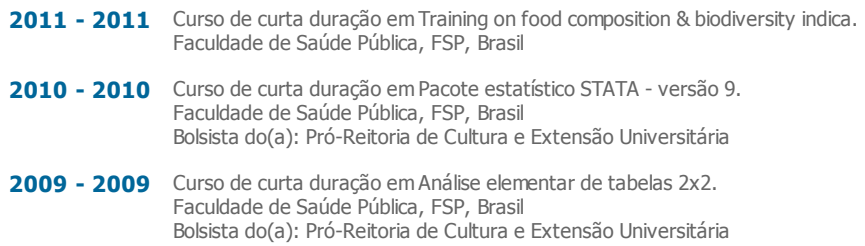


2007 - 2007 Curso de curta duração em Triagem Nutricional.

Equipe Multiprofissional de Terapia Nutricional - Hospital das Clínicas, EMTN-HC, Brasil Palavras-chave: Nutricional, triagem

2007 - 2007 Métodos de Avaliação do Estado Nutricional. Associação Paulista de Nutrição, APAN, Brasi Palavras-chave: Nutricional, Avaliação, população

\section{Atuação profissional}

1. Faculdade de Saúde Pública - FSP

Vínculo institucional

2012 - Atual Vínculo: Bolsista, Enquadramento funcional: Programa de Aperfeiçoamento do Ensino - PAE , Carga horária: 6, Regime: Parcial

2010 - 2010 Vínculo: monitor , Enquadramento funcional: monitor da dsciplina HNT 171 - Adm de UAN, Regime: Parcial

2009 - 2009 Vínculo: Representante discente, Enquadramento funcional: Comissão dos 70 anos do curso de nutrição, Regime: Parcial

2009 - 2009 Vínculo: monitor, Enquadramento funcional: monitor disciplina HNT 203 - Ed Nutricional, Regime: Parcial

2009 - 2009 Vínculo: monitor , Enquadramento funcional: monitor da dsciplina HNT 171 - Adm de UAN, Regime: Parcial

2008 - 2009 Vínculo: Representante discente, Enquadramento funcional: Departamento de Práticas de Saúde Pública, Regime: Parcial

2008 - 2010 Vínculo: Representante discente, Enquadramento funcional: Comissão USP-RECICLA-FSP, Regime: Parcial

2008 - 2010 Vínculo: Representante discente, Enquadramento funcional: Comissão de graduação, Regime: Parcial

2007 - 2007 Vínculo: estagiaria , Enquadramento funcional: CLINUT - Clínica de Atendimento Nutricional, Regime: Parcial

2007 - 2010 Vínculo: Iniciação científica, Enquadramento funcional: Bolsista FAPESP, Carga horária: 40, Regime: Dedicação exclusiva

2. Centro de Referência a Prevenção Controle de Doenças Associadas a Nutrição - CRNUTRI

Vínculo institucional

2010 - 2010 Vínculo: estagiaria, Enquadramento funcional: estagiaria de nutrição, Carga horária: 30, Regime: Parcial

3. Secretaria de Segurança Alimentar e Nutricional do município de Suzano - SESANA

\section{Vínculo institucional}

2010 - 2010 Vínculo: estagiaria, Enquadramento funcional: Estagiaria no progama Restaurante Popular , Carga horária: 30, Regime: Parcial

4. Instituto de Assistência Medica ao Servidor Público - IAMSPE

Vínculo institucional

2010 - 2010 Vínculo: estagiaria, Enquadramento funcional: estagiaria de nutrição, Carga horária: 30, Regime: Parcial

5. Associação Prato Cheio - APC

Vínculo institucional

2010 - 2010 Vínculo: estagiaria, Enquadramento funcional: estagiaria de nutrição, Carga horária: 30, Regime: Parcial

6. Executiva Nacional dos Estudantes de Nutrição - ENEN

\section{Vínculo institucional}

2008 - 2010 Vínculo: Coordenadora, Enquadramento funcional: Coordenadora Reginal - São Paulo, Regime: Parcial

7. Empório Santa Clara Pão e Vinho LTDA - SNTA CLARA

Vínculo institucional

2006 - 2007 Vínculo: Estagiária, Enquadramento funcional: Estagiária em Nutrição, Carga horária: 30, Regime: Parcial

1. Alimentação coletiva

2. Padrão alimentar 
Idiomas

Alemão Compreende Razoavelmente , Fala Razoavelmente, Escreve Razoavelmente, Lê Razoavelmente

Inglês Compreende Bem, Fala Pouco, Escreve Razoavelmente, Lê Bem

\section{Producão}

Produção bibliográfica

Artigos completos publicados em periódicos

1. If doi> GORGULHO, B. M., PREVIDELII, A. N., MARCHIONI, D.M.L.

Effects of an intervention in the workplace food environment. Nutrition \& Food Science. , v.42, p. 156 - 163, 2012

Palavras-chave: alimentação coletiva, trabalhadores, IQR

Referências adicionais : Inglês. Meio de divulgação: Vários

2. IT GORGULHO, B. M., MARCHIONI, D.M.L., CONCEIÇÃO, ADRIANA BAILAN, STELUTI, JOSIANE, MUSSI, MARINA, NAGAI, ROBERTA, Teixeira, LR, DA LUZ, ANDREA APARECIDA, FISCHER, FRIDA MARINA QUALITY OF DIET OF WORKING COLLEGE STUDENTS. Work (Reading, MA). JCR , v. 41, p.5806 - 5809, 2012.

Palavras-chave: trabalhadores, alimentação, jovem, universitario Referências adicionais : Inglês.

3. If GORGULHO, B. M., LIPI, M., MARCHIONI, D.M.L.

Qualidade nutricional das refeições servidas em uma Unidade de Alimentação e Nutrição de uma indústria da região metropolitana de São Paulo.. Revista de Nutrição (Impresso). JCR , v.24, p.463 - 472, 2011. Palavras-chave: alimentação, alimentação coletiva, trabalhadores

Referências adicionais : Português.

Artigos aceitos para publicação

1. MARCHIONI, D.M.L., Mendes, A, GORGULHO, B. M., STELLA, R. H., FISBERG, R.M. Densidade energética da dieta e fatores associados: como está a população de São Paulo?. Arquivos Brasileiros de Endocrinologia e Metabologia (Impresso). JCR, 2012. Referências adicionais : Português.

2. MARCHIONI, D.M.L., GORGULHO, B. M., PREVIDELI, A. N., LIPI, M. Energy density and diet quality among Brazilian workers. Nutrition \& Food Science. , 2012. Referências adicionais : Inglês.

Trabalhos publicados em anais de eventos (resumo)

1. Mendes, A, Martins, AC, de Castro MA, GORGULHO, B. M., FISBERG, R.M., MARCHIONI, D.M.L. ENERGY DENSITY AND CARDIOVASCULAR RISK FACTORS IN THE POPULATION OF SÃO PAULO In: INTERNATIONAL CONFERENCE ON DIT AND ACTIVITY METHODS, 2012, ROMA.

ABSTRACT BOOK. ROMA: FAO, 2012. p.120 - 121

Referências adicionais : Itália/Inglês. Meio de divulgação: Impresso

2. GORGULHO, B. M., Avelino, G, Valentine, P, FISBERG, R.M., MARCHIONI, D.M.L OUT-OF-HOME EATING PREVALENCE IN THE CITY OF SÃO PAULO, SOUTHEAST BRAZIL In: INTERNATIONAL CONFERENCE ON DIT AND ACTIVITY METHODS, 2012, ROMA. ABSTRACT BOOK. ROMA: FAO, 2012. p. 46 - 46 Referências adicionais : Itália/Inglês. Meio de divulgação: Impresso

3. PREVIDELU, A. N., ANDRADE, S. C., GORGULHO, B. M., VERLY JR, E., MARCHIONI, D.M.L. Population 's distribution scores of brazilian healthy eating index - revised components estimated by usual dietary intake among adolescents of São paulo, Brazil In: XVI Congresso Latinoamericano de Nutrição, 2012, Havana. SLAN. , 2012 Referências adicionais : Cuba/Inglês. Meio de divulgação: Vários

4. GORGULHO, B. M., CASTRO, M. A., FISBERG, R. M., MARCHIONI, D. M. L. Quality of the meals consumed out of home in the city of São Paulo, southeast Brazil In: XVI Congresso Latinoamericano de Nutrição, 2012, Havana.

SLAN. Havana: , 2012.

Referências adicionais : Cuba/Inglês. Meio de divulgação: Vários

5. VERLY JR, E., GORGULHO, B. M., Avelino, G, Mendes, A, FISBERG, R.M., MARCHIONI, D.M.L. THE USE OF AN INDICATOR VARIABLE RATHER THAN AN FFQ CAN BE USED TO ESTIMATE USUAL INTAKE OF FOOD EPISODICALLY CONSUMED In: INTERNATIONAL CONFERENCE ON DIT AND ACTIVITY METHODS, 2012, ROMA. 2012, ROMA.
ABSTRACT BOOK. , 2012. p. 232 - 232 Referências adicionais : Itália/Inglês. Meio de divulgação: Impresso

6. Avelino, G, de Castro MA, GORGULHO, B. M., Baltar, V, MARCHIONI, D.M.L., FISBERG, R.M. UNDERREPORTING OF ENERGY INTAKE IN ADULTS AND ELDERLY RESIDING IN THE CITY OS SÃO PAULO, BRAZIL In: INTERNATIONAL CONFERENCE ON DIT AND ACTIVITY METHODS, 2012, ROMA.

ABSTRACT BOOK. ROMA: FAO, 2012. p.137 - 138

Referências adicionais : Itália/Inglês. Meio de divulgação: Impresso

7. CARLOS, JAQUELINE VENANCIO, PREVIDELLI, A. N., GORGULHO, B. M., MARCHIONI, D.M.L Diet quality of male adult participants HIM study-Brazil (Natural History of HPV infection in men) multicentric study In: World Congress of Epidemiology, 2011, Edinburgh.

Journal of Epidemiology \& Community health. , 2011. v.65. p.a130 - a130 Referências adicionais : Escócia/Inglês. Meio de divulgação: Impresso

8. CARVALHO, ALINE MARTINS, VERLY JR, E., PREVIDELU, A. N., GORGULHO, B. M., MARCHIONI, D.M.L. FISBERG, R.M.

Processed meat consumed by brazilian adolescents: an analysis according to traffic light labelling In: World Congress of Epidemiology, 2011, Edinburgh.

Journal of Epidemiology \& Community health. , 2011. v.65. p.a429-a429 
Referências adicionais : Escócia/Inglês. Meio de divulgação: Impresso

9. BRUNACIO, KAROLINE HONORATO, VERLY JR, E., PIOVEZAN, LIVIA GONÇALVES, BIGIO, ROBERTA SCHEIN, GORGULHO, B. M., cesar, C.L.G., FISBERG, R.M., MARCHIONI, D.M.L.

USO DE SUPLEMENTOS DIETÉTICOS ENTRE RESIDENTES DO MUNICÍPIO DE SÃO PAULO In: $11^{\circ}$

CONGRESSO NACIONAL DA SOCIEDADE BRASILEIRA DE ALIMENTAÇÃO E NUTRIÇÃOO, 2011, FORTALEZA $\mathrm{CE}$.

$11^{\circ}$ CONGRESSO NACIONAL DA SOCIEDADE BRASILEIRA DE ALIMENTAÇÃO E NUTRIÇÃO. ,

Referências adicionais : Brasil/Português. Meio de divulgação: Meio digital

10. SELEM, S. C., de Castro MA, CARLOS, JAQUELINE VENANCIO, GORGULHO, B. M., MARCHIONI, D.M.L., FISBERG, R.M.

Validity of self-reported hypertension among brazilian adults In: World Congress of Epidemiology, 2011, Edinburgh.

Journal of Epidemiology \& community health. , 2011. v.65. p.A130 - A130

Referências adicionais : Escócia/Inglês. Meio de divulgação: Impresso

11. PREVIDELI, A. N., VERLY JR, E., CARLOS, JAQUELINE VENANCIO, GORGULHO, B. M., MARCHIONI

VARIAÇÃO TEMPORAL DA QUALIDADE DA DIETA DE UMA COORTE DE ADOLESCENTES RESIDENTES NO MUNICIPIO DE SÃO PAULO In: $11^{\circ}$ CONGRESSO NACIONAL DA SOCIEDADE BRASILEIRA DE ALIMENTAÇÃO E NUTRIÇÃO, 2011, FORTALEZA- CE.

$11^{\circ}$ CONGRESSO NACIONAL DA SOCIEDADE BRASILEIRA DE ALIMENTAÇÃO E NUTRIÇÃO. ,

2011.

Referências adicionais : Brasil/Português. Meio de divulgação: Meio digital

12. GORGULHO, B. M., PREVIDEUI, A. N., MARCHIONI, D.M.L.

Impacto de uma intervenção nutricional em ambiente de trabalho na qualidade da refeição In: II World Congress of Public Health Nutrition and I Latin American Congress of Community Nutrition, 2010, Porto. Public Health Nutrition. , 2010. v.13.

Referências adicionais : Portugal/Português. Meio de divulgação: Impresso

13. GORGULHO, B. M., LPI, M., MARCHIONI, D.M.L

Características das refeições servidas em uma Unidade de Alimentação e Nutrição de uma indústria da região metropolitana de São Paulo In: $17^{\circ}$ Simpósio Internacional de Iniciação Científica da USP, 2009 Ribeirão Preto.

$17^{\circ}$ Simpósio Internacional de Iniciação Científica da USP. , 2009.

Referências adicionais : Brasil/Português. Meio de divulgação: Meio digital

14. GORGULHO, B. M., LIPI, M., MARCHIONI, D.M.L

Principais caracteristicas das refeições servidas em uma unidade de alimentação e nutrição de uma industria da região metropolitana de São Paulo In: $10^{\circ}$ Congresso Nacional da Sociedade Brasileira de Alimentação e Nutrição, 2009, São Paulo.

Nutrire. , 2009.

Referências adicionais : Brasil/Português. Meio de divulgação: Meio digital

15. GORGULHO, B. M., LIPI, M., MARCHIONI, D.M.L.

Qualidade das refeições servidas em uma Unidade de Alimentação e Nutrição de uma industria da região metropolitana de São Paulo In: $140^{\circ}$ Congresso Nacional da Sociedade Brasileira de Alimentação e Nutrição, 2009, São Paulo.

Nutrire. , 2009

Referências adicionais : Brasil/Português. Meio de divulgação: Meio digital

16. VERLY JR, E., GORGULHO, B. M., cesar, C.L.G., FISBERG, R.M., MARCHIONI, D.M.L. Atividade Física e Hábitos de Vida de Adolescentes residentes no Município de São Paulo In: XVIII Congresso Mundial de Epidemiologia e VII Congresso Brasileiro de Epidemiologia, 2008, Porto Alegre. XVIII Congresso Mundial de Epidemiologia e VII Congresso Brasileiro de Epidemiologia. ,

Áreas do conhecimento : Nutrição

Referências adicionais : Brasil/Português.

17. GORGULHO, B. M., VERLY JR, E., cesar, C.L.G., FISBERG, R.M., MARCHIONI, D.M.L

Estado Nutricional e Insatisfação Corporal entre Adolescentes Residentes no Município de São Paulo. In: XVIII Congresso Mundial de Epidemiologia e VII Congresso Brasileiro de Epidemiologia, 2008, Porto Alegre. XVIII Congresso Mundial de Epidemiologia e VII Congresso Brasileiro de Epidemiologia. , 2008.

Areas do conhecimento : Nutrição

Referências adicionais : Brasil/Português.

18. GORGULHO, B. M., MARCHIONI, D.M.L.

Qualidade das refeições servidas em uma unidade de alimentação e nutrição de uma indústria da região metropolitana de São Paulo In: $16^{\circ}$ Simpósio Internacional de Iniciação Científica da USP, 2008, Ribeirão Preto.

$16^{\circ}$ Simpósio Internacional de Iniciação Científica da USP. , 2008.

Palavras-chave: industria, IQR, UAN

Areas do conhecimento : Nutrição

Setores de atividade : Saúde e Serviços Sociais

Referências adicionais : Brasil/Português. Meio de divulgação: Meio digital

Apresentação de trabalho e palestra

1. GORGULHO, B. M., Avelino, G, Valentine, P, FISBERG, R.M., MARCHIONI, D.M.L OUT-OF-HOME EATING PREVALENCE IN THE CITY OF SÃO PAULO, SOUTHEAST BRAZIL, 2012. (Conferência ou palestra,Apresentação de Trabalho)

Referências adicionais : Itália/Inglês. Meio de divulgação: Impresso; Local: FAO; Cidade: Roma; Evento: International Conference on Diet and Activity Methods; Inst. promotora/financiadora: Food and Agriculture Organization of the United Nations (FAO)

2. CARVALHO, ALINE MARTINS, SELEN, SORAYA, CARLOS, JAQUELINE VENANCIO, GORGULHO, B. M. FISBERG, R.M., MARCHIONI, D.M.L.

CONSUMO EXCESSIVO DE CARNES VERMELHAS E PROCESSADAS EM SÃO PAULO, 2011.

(Congresso, Apresentação de Trabalho)

Referências adicionais : Brasil/Português. Meio de divulgação: Meio digital; Cidade: FORTALEZA - CE; Evento: $11^{\circ}$ CONGRESSO NACIONAL DA SOCIEDADE BRASILEIRA DE ALIMENTAÇÃO E NUTRIÇÃO

3. GORGULHO, B. M., MARCHIONI, D.M.L., STELUTI, JOSIANE, CONCEICÃO, ADRIANA BAILAN, MUSSI, MARINA, NAGAI, ROBERTA, MATSUMURA, ROBERTO JUN, DA LUZ, ANDREA APARECIDA, FISCHER, FRIDA MARINA

QUALIDADE DA DIETA DE JOVENS TRABALHADORES NO MUNICÍPIO DE SÃO PAULO, 2011.

(Congresso, Apresentação de Trabalho)

Referências adicionais : Brasil/Português. Meio de divulgação: Meio digital; Cidade: Fortaleza - CE; Evento:

$11^{\circ}$ Congresso Nacional da Sociedade Brasileira de Alimentação e Nutrição

4. GORGULHO, B. M.

Conjugando saberes e competências do nutricionista, 2009. (Simpósio,Apresentação de Trabalho) 
Referências adicionais : Brasil/Português. Meio de divulgação: Outro; Local: Centro Universitário São Camilo; Cidade: São Paulo; Evento: Simposio ASBRAN 60 anos; Inst. promotora/financiadora: Associação Brasileira de Nutrição

5. GORGULHO, B. M., VERLY JR, E., cesar, C.L.G., FISBERG, R.M., MARCHIONI, D.M.L Estado Nutricional e Insatisfação Corporal entre Adolscentes residentes no Município de São paulo, 2008. (Outra,Apresentação de Trabalho) paulo, 2008. (Outra, Apresentaçãã

Referências adicionais : Brasil/Português; Local: UNICAMP; Cidade: Campinas; Evento: II Encontro dos Inquéritos de Saúde ISA; Inst. promotora/financiadora: UNICAMP

Produção técnica

Redes sociais, websites, blogs

1. MARChIONI, D.M.L., PREVIDEUI, A. N., Martins, AC, Mendes, A, GORGULHO, B. M., VERLY JR, E., STELUTI, JOSIANE, Avelino, G, de Castro MA, Baltar, V, FISBERG, R.M. Grupo de Pesquisa de Avaliação do Consumo alimentar, 2012

Referências adicionais : Brasil/Português. . Home page: http://www.gac-usp.com.br/

Produção artística/cultural

Outra produção artística/cultural

1. GORGULHO, B. M., JANUARIO, B. L., KAWAMURA, K. S., BUENO, C., Borali, C

Evento: Minuto Nutrição, 2008. Cidade do evento: São Paulo. País: Brasil. Duração: 2.

Palavras-chave: alimentação saudável, educação nutricional, adulto

Áreas do conhecimento : Educação Nutricional

Setores de atividade : Educação, Saúde e Serviços Sociais

Referências adicionais : Brasil/Português.

Educação e Popularização de C\&T

Redes sociais, websites e blogs

1. MARCHIONI, D.M.L., PREVIDEUI, A. N., Martins, AC, Mendes, A, GORGULHO, B. M., VERLY JR, E., STELUTI, JOSIANE, Avelino, G, de Castro MA, Baltar, V, FISBERG, R.M.

Grupo de Pesquisa de Avaliação do Consumo alimentar, 2012. (Blog, Mídias sociais, websites, blogs)

Referências adicionais : Brasil/Português. . Home page: http://www.gac-usp.com.br/

\section{Eventos}

Eventos

Participação em eventos

1. Apresentação Oral no(a) INTERNATIONAL CONFERENCE ON DIT AND ACTIVITY METHODS, 2012 (Congresso)

OUT-OF-HORM EATING PREVALENCE IN THE CITY OF SÃO PAULO, SOUTHEAST BRAZIL.

2. Apresentação Oral no(a) $\mathbf{1 1}^{\circ}$ CONGRESSO NACIONAL DA SOCIEDADE BRASILEIRA DE ALIMENTAÇÃO E NUTRIÇÃO, 2011. (Congresso) CONSUMO EXCESSIVO DE CARNES VERMELHAS E PROCESSADAS EM SÃO PAULO.

3. Apresentação Oral no(a) $\mathbf{1 1}^{\circ}$ Congresso Nacional da Sociedade Brasileira de Alimentação e Nutrição, 2011. (Congresso) QUALIDADE DA DIETA DE JOVENS TRABALHADORES NO MUNICÍPIO DE SÃO PAULO.

4. Apresentação de Poster / Painel no(a) World Congress of Epidemiology, 2011. (Congresso) Validity of self-reported hypertension among brazilian adults.

5. II Seminario Inquéritos de Saúde no municipio de São Paulo ISA, 2011. (Seminário)

6. Apresentação (Outras Formas) no(a)10 Congresso Municipal de Educação de Suzano, 2010. (Congresso) Educação Nutricional.

7. Apresentação de Poster / Painel no(a) II World Congress of Public Health Nutrition and I Latin American Congress of Community Nutrition, 2010. (Congresso)

Impacto de uma intervenção nutricional em ambiente de trabalho na qualidade da refeição.

8. Apresentação de Poster / Painel no(a) XVII Simpósio Internacional de Iniciação Científica da USP, 2009. (Simpósio)

Características das refeições servidas em uma Unidade de Alimentação e Nutrição de uma indústria da região metropolitana de São Paulo.

9. Apresentação de Poster / Painel no(a) $10^{\circ}$ Congresso Nacional da Sociedade Brasileira de Alimentação e Nutrição, 2009. (Congresso) Prinipais Caracteristicas da refeição servida em uma Unidade de Alimentação e Nutrição de uma indústria da região metropolitana de São paulo.

10. Apresentação (Outras Formas) no(a)Oficina de Trabalho: Projeto Político Pedagógico e Estrutura Curricular do Curso de Nutrição da USP, 2009. (Oficina) 
Projeto Político Pedagógico e Estrutura Curricular do Curso de Nutrição da USP.

11. Pesquisa e ensino em nutrição no séc XXI: do ambiente à genética, 2009. (Seminário)

12. Pesquisa e ensino em Nutrição no seculo XXI: do ambiente à genética, 2009. (Seminário)

13. Apresentação de Poster / Painel no(a) XVIII Congresso Mundial de Epidemiologia e VII Congresso Brasileiro de Epidemiologia, 2008. (Congresso) Atividade Física e Hábitos de vida de adolescentes residentes no municipio de São paulo.

14. Apresentação Oral no(a) II Encontro dos Inquéritos de Saúde ISA, 2008. (Encontro) Estado Nutricional e Insatisfação Corporal entre adolescentes residendes no Município de São Paulo.

15. Apresentação de Poster / Painel no(a) XVIII Congresso mundial de Epidemiologia e VII Congresso brasileiro de Epidemiologia, 2008. (Congresso)

Estado Nutricional e insatisfação corporal entre adolescentes residentes no municipio de São Paulo.

16. Apresentação de Poster / Painel no(a) $16^{\circ}$ Simpósio Internacional de Iniciação Científica da USP, 2008. (Simpósio)

Qualidade das refeições seridas em uma unidade de alimentação e nutrição de um industria da região me tropolitana de São Paulo.

17. XXV Encontro Nacional dos Estudantes de Nutrição, 2008. (Encontro)

18. Defesa de Tese de Mestrado: Densidade energética da dieta de trabalhadores de uma indústria da região metropolitana de São Paulo., 2008. (Outra)

19. Defesa de Tese de Mestrado: Consumo de alimentos industrializados e fatores associados em adultos e idosos residentes no município de São Paulo., 2008. (Outra)

20. I Jornada sobre Tabelas de Composição e Cálculo Informatizado de Dietas, 2008. (Outra)

21. I Ciclo de Nutrição e Carreira, 2008. (Outra)

22. Diet and Breast Cancer: methodological issues in nutritional epidemiology, 2008. (Outra)

23. Diet and Prevention of Coronary Heart Disease, 2008. (Outra)

24. Defesa de Tese de Mestrado: Densidade energética: relação com variáveis demográficas, de estilo de vida, nutricionais e socioeconômicas em amostra representativa da população adulta no município de São Paulo., 2008. (Outra)

25. XXIV Encontro Nacional de Estudantes de Nutrição, 2007. (Encontro)

26. $4^{\circ}$ Congresso Paulista de Nutrição, 2007. (Congresso)

27. Importância do Consumo de Leite para o ser Humano: mitos e verdades, 2007. (Simpósio)

28. Seminário de Transtornos Alimentares, 2007. (Seminário)

29. Publicidade de Alimentos: Participando da Construção de uma Política Pública, 2007. (Seminário)

30. $3^{\circ}$ Encontro de pesquisa e Pós-Graduação, 2007. (Encontro)

31. I Simpósio da Liga Universitária de Nutrição São Camilo, 2006. (Simpósio)

Organização de evento

1. GORGULHO, B. M.

XXVI Encontro Nacional dos Estudantes de Nutrição, 2009. (Outro, Organização de evento)

Palavras-chave: SAN

Áreas do conhecimento : Nutrição

Referências adicionais : Brasil/Português. Meio de divulgação: Vários

Totais de produção

\begin{tabular}{|c|c|}
\hline Artigos completos publicados em periódico & 3 \\
\hline Artigos aceitos para publicação & 2 \\
\hline Trabalhos publicados em anais de eventos & 18 \\
\hline Apresentações de trabalhos (Conferência ou palestra) & 1 \\
\hline Apresentações de trabalhos (Congresso) & 2 \\
\hline Apresentações de trabalhos (Simpósio) & 1 \\
\hline Apresentações de trabalhos (Outra) & 1 \\
\hline
\end{tabular}


Produção técnica

Blog

Eventos

Participações em eventos (congresso)

Participações em eventos (seminário)

5

Participações em eventos (simpósio)

Participações em eventos (oficina)

Participações em eventos (encontro)

1

Participações em eventos (outra)

Organização de evento (outro)

Produção artística/cultural

Outra produção artística/cultural

Página gerada pelo sistema Currículo Lattes em 29/11/2012 às 17:59:16. 